\title{
A Sweeping Jet Application on a High Reynolds Number Semispan Supercritical Wing Configuration
}

\author{
Gregory S. Jones, ${ }^{1}$ William E. Milholen, $\mathrm{II},{ }^{2}$ David T. Chan, ${ }^{3}$ \\ Latunia Melton, ${ }^{4}$ Scott L. Goodliff, ${ }^{5}$ C. Mark Cagle ${ }^{6}$ \\ NASA Langley Research Center, Hampton, VA, 23681
}

\begin{abstract}
The FAST-MAC circulation control model was modified to test an array of unsteady sweeping-jet actuators at realistic flight Reynolds numbers in the National Transonic Facility at the NASA Langley Research Center. Two types of sweeping jet actuators were fabricated using rapid prototype techniques, and directed over a $15 \%$ chord simple-hinged flap. The model was configured for low-speed high-lift testing with flap deflections of $30^{\circ}$ and $60^{\circ}$, and a transonic cruise configuration having a $0^{\circ}$ flap deflection. For the $30^{\circ}$ flap high-lift configuration, the sweeping jets achieved comparable lift performance in the separation control regime, while reducing the mass flow by $54 \%$ as compared to steady blowing. The sweeping jets however were not effective for the $60^{\circ}$ flap. For the transonic cruise configuration, the sweeping jets reduced the drag by $3.3 \%$ at an offdesign condition. The drag reduction for the design lift coefficient for the sweeping jets offer is only half the drag reduction shown for the steady blowing case (6.5\%), but accomplished this with a $74 \%$ reduction in mass flow.
\end{abstract}

\begin{tabular}{|c|c|c|c|}
\hline \multicolumn{4}{|c|}{ Nomenclature } \\
\hline b & $=$ wing span (in) & $\mathrm{U}_{\text {EXIT }}$ & $=$ average sweeping jet-exit velocity $(\mathrm{ft} / \mathrm{sec})$ \\
\hline CFD & $=$ Computational Fluid Dynamics & $\mathrm{U}_{\mathrm{EXIT}(\mathrm{HW})}=$ & $=$ sweeping jet-exit velocity, hot wire $(\mathrm{ft} / \mathrm{sec})$ \\
\hline$C_{p}$ & $=$ pressure coefficient & $\mathrm{U}_{\text {THROAT }}=$ & $=$ sweeping jet throat velocity $(\mathrm{ft} / \mathrm{sec})$ \\
\hline $\mathrm{c}$ & $=$ chord (in) & USM3D & $=$ unstructured Navier Stokes 3D flow solver \\
\hline $\mathrm{C}_{\text {DIS }}$ & $=$ nozzle discharge coefficient & $\mathrm{W}_{\mathrm{I}} \quad=$ & $=$ ideal weight flow $(\mathrm{lbm} / \mathrm{sec})$ \\
\hline $\mathrm{C}_{\mu}$ & $=$ momentum coefficient for steady jet & $\mathrm{w}_{\mathrm{M}}$ & $=$ measured weight flow $(1 \mathrm{bm} / \mathrm{sec})$ \\
\hline$\overline{\mathrm{C}}_{\mu}$ & $=$ average momentum coefficient for & $\alpha$ & $=$ angle of attack (degrees) \\
\hline $\mathrm{h}$ & $\begin{aligned} & \text { sweeping jet at jet-exit } \\
= & \text { nozzle throat exit height (in) }\end{aligned}$ & $\eta$ & $=$ span location $/ \mathrm{b}$ \\
\hline $\mathrm{M}_{\infty}$ & $=$ wind tunnel Mach number & & \\
\hline NPR & $=$ nozzle pressure ratio $\left(\mathrm{P}_{\mathrm{o}(\mathrm{J})} / \mathrm{P}_{\infty}\right)$ & & \\
\hline $\mathrm{P}_{\mathrm{o}(\mathrm{J})}$ & $=$ jet total pressure $(\mathrm{psi})$ & & \\
\hline $\mathrm{P}_{\mathrm{o}(\mathrm{THROAT})}$ & $=$ throat total pressure $(\mathrm{psi})$ & & \\
\hline$P_{\infty}$ & $=$ wind tunnel static pressure $(\mathrm{psi})$ & & \\
\hline$q_{\infty}$ & $=$ freestream dynamic pressure $(\mathrm{psf})$ & & \\
\hline $\operatorname{Re}_{\mathrm{C}}$ & $=$ chord Reynolds number & & \\
\hline S & $=$ wing plan form area & & \\
\hline SMSS & $=$ Sidewall Model Support System & & \\
\hline & $=$ wind tunnel total temperature $\left({ }^{\circ} \mathrm{R}\right)$ & & \\
\hline $\mathrm{T}_{\mathrm{O}(\mathrm{JET})}$ & $=$ jet total temperature $\left({ }^{\circ} \mathrm{R}\right)$ & & \\
\hline $\mathrm{U}_{\mathrm{JET}}$ & $\begin{aligned}= & \text { throat jet velocity for steady blowing } \\
& \text { configuration }(\mathrm{ft} / \mathrm{sec})\end{aligned}$ & & \\
\hline
\end{tabular}

\footnotetext{
${ }^{1}$ Research Engineer, Configuration Aerodynamics Branch, Mail Stop 267, AIAA Associate Fellow

${ }^{2}$ Research Engineer, Configuration Aerodynamics Branch, Mail Stop 499, AIAA Senior Member

${ }^{3}$ Research Engineer, Configuration Aerodynamics Branch, Mail Stop 499, AIAA Senior Member

${ }^{4}$ Research Engineer, Flow Physics and Control Branch, Mail Stop 170, AIAA Associate Fellow

${ }^{5}$ Test Engineer, Jacobs Technology, Inc., Mail Stop 267, AIAA Senior Member

${ }^{6}$ Design Engineer, Aeronautics Systems Engineering Branch, Mail Stop 238
} 


\section{Introduction}

$\mathrm{T}$ he study of circulation control has a long history, ${ }^{1,2,3,4,5}$ but it has not been applied to commercial aircraft due to system requirements that include the air source (i.e., engine bleed), design complexity, weight penalties, engineout conditions, etc. Application of these blowing systems to takeoff and landing configurations have been demonstrated in a laboratory environment for boundary layer separation management, which led to improved performance. However, those benefits have not crossed the cost/benefit threshold for this technology to buy its way onto an aircraft for the high-lift applications alone. It has become more apparent that the trade studies of circulation control applied to high-lift and cruise configurations are closely coupled, and the combined performance would be enough to overcome the barriers to its application to commercial aircraft. The realization of improved cruise efficiency at realistic flight conditions potentially changes the paradigm for circulation control applications.

This paper will focus on the application of sweeping jets to high-lift and cruise configurations with the intent of achieving the flight performance of a vehicle with minimal bleed requirements. It is also imperative to evaluate the benefits of these advanced active flow control (AFC) systems at realistic flight conditions that include Mach number and Reynolds number. It is also recognized that Computational Fluid Dynamics (CFD) has become an integral part of the aircraft design process, and those codes require a benchmark data set (such as circulation control described below) to be a part of the validation process. ${ }^{6,7,8}$ When applying AFC systems to scaled models, it is critical that the flow at the intersection of the outer mold line (OML) and the jet-exit is representative of the actual flight vehicle. Since the performance is typically characterized in terms of nondimensional forces and the jet momentum coefficient, it is necessary to profile the weight flow and velocity of the jet. This paper will also focus on reducing the weight flow requirements established with steady blowing associated with the Fundamental Aerodynamic Subsonic Transonic-Modular Active Flow (FAST-MAC) model using a sweeping jet technology. This model utilized an advanced circulation control high-lift and cruise system that has been tested multiple times in the NASA Langley National Transonic Facility (NTF) shown in Figure 1.

The circulation control methods that will be discussed throughout this paper introduces momentum directly to the near-wall region via a blowing slot, located near the wing trailing edge, and directed over a simple short-chord hinged-flap as shown in Figure 2. For steady circulation control applications, the flow is typically characterized by jet momentum $\left(\mathrm{C}_{\mu}\right)$ or nozzle pressure ratio (NPR) that defines the jet velocity $\left(\mathrm{U}_{\text {THROAT }}\right)$ at the minimum area along the flow path. The minimum area is located at the jet-exit for the steady blowing configuration. The jet momentum is generally related to ideal conditions as shown in Equation 1, where internal boundary layer growth is ignored and weight flow is a function of the total pressure measured in the settling chamber of the aft plenum. The jet momentum can also be characterized by using the measured weight flow and the nozzle discharge coefficient as shown in Equation 2. The average jet velocity used in Equations 1 and 2 assumes that the flow expands isentropically to the freestream static pressure and is characterized by the NPR and jet temperature $\left(\mathrm{T}_{\mathrm{O}(\mathrm{JET})}\right)$ shown in Equation 3. Figure 3 shows a schematic of a sweeping jet actuator, which creates a self-sustaining oscillating jet, due to the feedback tubes alternating the internal flow path direction in the exit nozzle. The minimum throat area is now inside the actuator, and not at the exit plane. The timedependent external velocity field of the sweeping jet is difficult to measure. For these reasons, the calculation of a momentum coefficient for the sweeping jet was modified, using an average exit velocity (Equation 4) instead of the throat velocity as follows.

The correlation of the performance that is measured by the balance is based on the averaged $\mathrm{C}_{\mu}$ at the exit of the nozzle. However, the measured NPR and jet velocity are based on the nozzle throat characteristics. For the steady blowing configuration, the throat is located at the jet-exit, but for the sweeping jet the throat is upstream of the jet-exit. This complicates the definition of $\mathrm{U}_{\text {EXIT }}$ used in the calculation of $\mathrm{C}_{\mu}$. The hot-wire measurement of the averaged jet velocity $\left(\mathrm{U}_{\mathrm{EXIT}(\mathrm{HW})}\right)$ along the exit plane of the entire wing span has not yet been completed. As such, the values used for $U_{\text {EXIT }}$ will be

$$
\begin{aligned}
& C_{\mu}=\frac{T H R U S T}{q_{\infty} S}=\frac{2 h z}{\bar{c} b} \frac{\rho_{J E T}}{\rho_{\infty}} \frac{U_{J E T}^{2}}{U_{\infty}^{2}} \\
& C_{\mu}=\frac{W_{M} U_{E X I T}}{q_{\infty} S}=\frac{C_{D I S} W_{I} U_{E X I T}}{q_{\infty} S}
\end{aligned}
$$

$$
\begin{aligned}
& U_{T H R O A T}=\sqrt{\frac{2 \gamma R T_{O(J E T)}}{\gamma-1}\left[1-\left(\frac{1}{N P R}\right)^{\frac{\gamma-1}{\gamma}}\right]} \\
& U_{E X I T}=U_{T H R O A T}\left(\frac{U_{E X I T(H W)}}{U_{T H R O A T}}\right) \\
& N P R=\frac{P_{O(T H R O A T)}}{P_{\infty}}
\end{aligned}
$$

based on the ratio of the measured average velocity across the exit of a bench-top mounted single actuator, and the throat velocity of the actuator in quiescent conditions shown in Figure 4. The magnitude of the sweeping jet velocity at the nozzle exit plane is a function of the sweeping jet diffuser and is not uniformly distributed at the exit of the sweeping jet ${ }^{9}$ as shown from hot wire measurements. The 
time averaged velocity profiles shown in Figure 4 are averaged across the exit plane of the actuator to determine the averaged jet-exit velocity shown in Figure 5.

The steady performance results of the FAST-MAC model used as a baseline for this paper were acquired from two test entries that are described in references 10 and 11 . Figure 6 highlights the low-speed high-lift performance observed with the steady blowing characteristics of the model. While NPR establishes the velocity at the jet-exit for the steady blowing configuration, it is the momentum coefficient that is best used to collapse the model performance. The remainder of this paper will focus on the unsteady characteristics of the sweeping jet configuration as they relate to the separation control $\left(\mathrm{C}_{\mu}<0.04\right)$ conditions of the FAST-MAC model.

\section{Experimental Setup}

\section{a.Wind Tunnel}

The $\mathrm{NTF}^{12}$ (Figure 7) is one of a limited number of wind tunnel facilities that can achieve flight Reynolds numbers and Mach numbers for transport type aircraft for both cruise and high-lift operations. The tunnel is a fandriven, closed-circuit, continuous-flow, pressurized wind tunnel capable of operating either in dry air at warm temperatures or in nitrogen gas from warm to cryogenic temperatures. The test section is $8.2 \mathrm{ft}$ by $8.2 \mathrm{ft}$ in cross section and $25 \mathrm{ft}$ in length. The test section floor and ceiling are slotted (6 percent open), and the sidewalls are solid. The wind tunnel is capable of an absolute pressure range from 1 atmosphere to 8.3 atmospheres, a temperature range from $-270^{\circ} \mathrm{F}$ to $130^{\circ} \mathrm{F}$, a Mach number range from 0.1 to 1.2 , and a maximum Reynolds number of $146 \times 10^{6}$ per foot at Mach 1. For the blowing test described in this paper, the temperature envelope was limited to $-50^{\circ} \mathrm{F}$ to $120^{\circ} \mathrm{F}$ due to limitations of the model protection system.

\section{b. FAST-MAC Model}

The FAST-MAC model shown in Figure 8 is based on a supercritical wing that was designed to become an NTF standard for evaluating performance characteristics of integrated active flow control and propulsion systems. The modular design and construction of the FAST-MAC model provides a capability of changing the leading edge, trailing edge, upper skin geometry (with or without engine simulators), and active or passive flow control technology. The outer mold line (OML) of the model was optimized for a cruise Mach number of 0.85 and a lift coefficient of 0.50 at a Reynolds number based on mean aerodynamic chord of $30 \times 10^{6}$. The design utilized an unstructured Navier-Stokes flow solver USM3D ${ }^{13}$ in conjunction with the CDISC design code. ${ }^{14}$ The CDISC design method is highly efficient because the geometry changes are introduced in a manner that allows both the geometry and the simulated aerodynamic analysis to converge in unison. The flow was assumed to be fully turbulent, and a wall-function version of the Spalart-Allmaras turbulence model was employed. A tangential blowing slot was added at the $85 \%$ chord location on the upper surface, and it was directed over a $15 \%$ chord simple-hinged flap for both the cruise and high-lift modes.

Figure 9 shows the cutaway view of the FAST-MAC semispan model geometry. A cross section view of the flap region is also shown for the three available flap deflections: $0^{\circ}$ cruise, and the low-speed deflection of $30^{\circ}$ and $60^{\circ}$ for high-lift. A fixed slat geometry is used for all high-lift testing, and was optimized for the $60^{\circ}$ flap. The wing has an aspect ratio of 5.0, taper ratio of 0.40 , leading edge sweep of $30^{\circ}$, and no dihedral. The chord length at the side of the fuselage is 25.0 inches, resulting in a mean aerodynamic chord of 19.4 inches. The generic fuselage is comprised of circular cross sections with a maximum width of 4.0 inches. The wing is mounted in the midfuselage position to simplify the routing of the high-pressure air supply lines. To reduce wall boundary layer effects, the model was offset from the tunnel sidewall using a 2.0 -inch nonmetric standoff, ${ }^{15}$ which has a profile shape identical to that of the fuselage centerline.

The model design criteria were to operate at the maximum pressure limits of the facility and a temperature range of $-50^{\circ} \mathrm{F}$ to $120^{\circ} \mathrm{F}$. While a typical NTF wind tunnel model such as the FAST-MAC accurately characterizes outer mold lines (OML) of an advanced high Reynolds number wing model, the internal flow paths are only representative at the jet-exit. High dynamic pressures are generally required to achieve high Reynolds number conditions for a typical semispan NTF model as shown in Figure 10. As such, the high model loading and resulting high model stresses limited accurate internal flow path geometries due to strength of materials and limited volume for the NTF FAST-MAC model. 


\section{c.Sweeping Jet Actuators}

The FAST-MAC model was modified to replace the steady blowing configuration with a design which integrated 39 interchangable actuator cartridges into the aft plenum cover as shown in Figure 11. Typically, the exit height of the jet would correspond to a constant $\mathrm{h} / \mathrm{c}$ of 0.0021 , and this resulted in a slot height variation of the cartridges along the span to maintain that specification. Unfortunately, fabrication limitations restricted the wall thickness of the outboard actuators to a constant height of 0.040 inches, resulting in flow paths three and four to have a varying $\mathrm{h} / \mathrm{c}$ as shown in Table 1 .

The actuator spacing, orientation, and location of the actuators used in this test were influenced by the work of Woszidlo et al. ${ }^{16}$ where a parametric study of the sweeping jet actuator used a $2 \mathrm{D}$ geometry. Melton ${ }^{17}$ applied a similar spacing for a swept model and this was used as a guide for the current test. However, spacing of the FASTMAC cartridges was restricted due to internal structures that held the plenum cover onto the wing. The ratio of the average distance between cartridges and actuator exit width varied from the wing root to tip as seen in Table 1 . The spacing ratio of the distance between centers and the nozzle exit was grouped into three sections based on actuator sizes. This resulted in spacing ratios of 1.6 for the inboard flow path, 2.1 for the midspan actuators, and 1.7 for the outboard two flow paths.

Two actuator configurations (shown in Figure 12) were used throughout the test, and they were optimized based on the actuator authority, which is defined as the sweep range across the flap. Actuator A has a total sweep angle of $\theta= \pm 45^{\circ}$, while actuator AA has a sweep angle of $\theta= \pm 35.5^{\circ}$. Pretest work relating to the design and laboratory testing of actuator performance in a quiescent environment is described in references 9,18 , and 19 . The Actuator A configuration focused on the application to high-lift whereas the Actuator AA geometry was intended for the cruise configuration. Differences in the estimated mass flow requirements for the cruise configuration and the high- lift configuration at a comparable NPR resulted in geometry differences between the two actuator designs. Indeed, the throat area of the cruise geometry was 1.877 times larger than the high-lift geometry resulting in a greater mass flow capability for cruise conditions as highlighted in Figure 13.

Two different fabrication techniques were implemented for the sweeping jet cartridges. Initially, it was believed that the temperature variations expected during the test would deform the actuators unless a metal configuration was used. The metal actuator cartridges (shown in Figure 14) were built using a hybrid electrical discharge machining $(E D M) /$ plating process. A 300-series stainless steel material was used for components that were nickel electroplated to provide strength and a thermally compatible base. The stainless steel surrounding structure and internal flow islands were machined via wire EDM to provide a press fit with an erodible aluminum mandrel. The assembly was then nickel electroformed to build-up the desired finish contour thickness before being machined to the correct planform and aerodynamic contour dimensions. Finally, the aluminum mandrel was etched away in a caustic bath, leaving the flow path embedded in the stainless steel/nickel structure. The stainless steel was pretreated before assembly to maximize adhesion to the nickel, producing a near homogeneous structure.

When those cartridges were installed into the FAST-MAC model, the standard bolt torque was too great and cracks formed in the electroformed material. Those cracks created an unacceptable leak path resulting in the decision to rebuild the cartridges using a plastic stereolithography (SLA) rapid prototyping technique. It was determined that the manufacturing tolerance of the SLA sweeping jet actuators could be maintained to within \pm 0.001 inch. That equated to $\pm 2.5 \%$ of the smallest throat dimension to be used in the FAST-MAC model. To verify that the cold environment of the tunnel would not visibly alter the geometry of the plastic SLA actuator cartridges, a frequency test was performed in a cryogenic test chamber at 3 times the expected pressure, which was limited by leaks at the actuator gasket. An example of the temperature effect on the sweeping frequency is shown in Figure 15, while the pressure effect or NPR is shown in Figure 16. The extremely cold temperature and elevated pressure did not alter the geometry of the actuator. However, when the actuator was exposed to warm temperatures greater than $140^{\circ} \mathrm{F}$, the thin upper skin of the actuator would deform and become wavy. To avoid this problem, cool air was continuously blown through the actuator when tunnel temperatures exceeded $120^{\circ} \mathrm{F}$.

The actuator Sound Pressure Levels (SPL) were also evaluated in the laboratory prior to installation in the model. Figure 17 highlights an example of the SPL for the two actuator geometries used in this test series. The higher mass flow through actuator AA created a $5 \mathrm{~dB}$ higher SPL than actuator A at the highest NPR. 


\section{d. Air Delivery System}

The dual flow air delivery system ${ }^{20}$ is a high-pressure air system that provides a continuous source of clean, dry air to the test article through the Sidewall Model Support System (SMSS). The FAST-MAC model utilized only the high-flow leg of this system as shown in the schematic in Figure 18, and it is equipped with coarse and fine control valves that can provide flow rates up to $23 \mathrm{lbm} / \mathrm{sec}$. The system has a multiple critical venturi (MCV) system located outside the tunnel plenum to measure the total weight flow. The total temperature of the model air stream can be set from $20^{\circ} \mathrm{F}$ to $120^{\circ} \mathrm{F}$ by using a steam heating system. The FAST-MAC model was designed to enable the flow to be tailored along the span by independently controlling the flow through any combination of the four flow paths distributed along the span of the wing. The challenge for this test was the ability to set the very low flow rates identified in Figure 13. This was accomplished by balancing the NPR settings with the model valves while using the fine flow control valve and the smallest venturi in the MCV. The jet-exit total pressure parameters used in the calculation of the throat velocity and $\mathrm{C}_{\mu}$ have measurement uncertainties that are less than $\pm 0.1 \%$ of reading for the range of flow conditions tested. The weight flow measured in the NTF air station by the MCV system has an uncertainty of $\pm 0.35 \%$ of reading. ${ }^{21}$

\section{e. Balance System}

The NTF $117 \mathrm{~S}$ is a 5-component balance that is mounted inside the SMSS as shown in Figure 19. The SMSS provides a heated enclosure that maintains a stable temperature for the balance and the pitch mechanisms. The balance characteristics are highlighted in Table 2.

The entire SMSS/balance/air system was calibrated to determine the pressurization and temperature effects of the Pressure Interface Piece (PIP). The calibration included the range of pressures needed for this sweeping jet test series. Those pressure tares are subtracted from the balance data to obtain pure aerodynamic loads. ${ }^{22}$, ${ }^{23}$ Recent improvements in the balance temperature control and other SMSS modifications resulted in a transonic 2-sigma drag repeatability of \pm 3 counts. ${ }^{24,}{ }^{25}$ Those improvements were necessary to meet the requirements for this sweeping jet study due to the small blowing effects associated with the separation control region of the FAST-MAC high-lift system and the cruise drag benefits in the range of Mach $=0.85-0.88$.

\section{Performance Results}

In propulsion simulation or testing that involves blowing concepts, the force and moment data acquired from a strain gauge balance frequently include the effects of the static thrust from the nozzle. In the cases where the thrust is metric (i.e. sensed and measured by the balance), the effect of the static thrust needs to be removed from the windon balance measurements to isolate the pure aerodynamic and jet-induced effects in the force and moment data. The data shown in this report will focus on the pure aerodynamic effects where the thrust is removed. The procedure for this thrust removal is described in Reference 26.

\section{a. High-lift results}

\section{Sweeping jet configuration for the $30^{\circ}$ flap}

As discussed above, the focus of the high-lift testing was to determine if the sweeping jet actuators would perform adequately in the separation control regime. Given the recent upgrades to the force and moment measurement system, the model was first configured to repeat the steady blowing configuration with the original nondimensional slot height of $\mathrm{h} / \mathrm{c}=0.0021$. The focus of these data will be on the change in lift that is referenced to the nonblowing condition.

After a limited number of steady blowing runs were completed, the new plenum cover plate shown in Figure 20 was installed to allow the sweeping jet cartridges to be evaluated. The actuator A configuration was installed first and a brief study performed to determine if all of the outboard cartridges were required. It should be noted that extra cartridges were included toward the wingtip for the transonic testing, anticipating a larger mass flow requirement to achieve shock movement. This study closed off the middle actuator of each "trio" grouping using a solid gasket at the cartridge inlet. The resulting spacing of active cartridges mimicked the spacing in the two inboard plenums. The results clearly demonstrated that all cartridges were required to attach the flow at the outboard portion of the flap. The following results were obtained with all sweeping jet cartridges active. 
The region of interest for this study was limited to the separation control regime that ends at approximately a $\mathrm{C}_{\mu}=0.02$ and $\Delta \mathrm{C}_{\mathrm{L}}$ of 0.4 for the $30^{\circ}$ flap. A comparison of the lift performance for the two sweeping actuator configurations with the steady blowing configuration for the $30^{\circ}$ flap deflection at $0^{\circ}$ angle of attack is shown in Figure 21. The two sweeping jet configurations were comparable to each other but at a lower momentum coefficient than the steady configuration, indicating a potential 55\% lower mass flow of the sweeping jets to achieve the same lift as the steady blowing configuration. Actuator AA was able to replicate the lift coefficient increment of 0.40 at the end of the separation control regime, while the Actuator A fell short by $20 \%$. It should be clearly noted that the ending point for each sweeping jet mass flow sweep was based on the pressure safety limit of the model hardware, and not the available mass flow from the model supply piping. Recall that the actuator AA was designed to have a larger throat area, and thus provide a higher mass flow for a given supply nozzle pressure ratio. This increase in mass flow for the actuator AA accounts for the higher lift increment. For a comparable lift increment, the actuator $\mathrm{A}$ is more efficient as it operates at a lower value of $\mathrm{C}_{\mu}$. Figure 22 presents the same results in terms of nozzle pressure ratio which can be related to the throat velocity of each configuration. It should be noted that the average jet velocity used to determine the momentum coefficient at the exit plane of the sweeping jet actuators is significantly less that the throat velocity as described by Equation 4 . Figure 23 highlights the $\Delta C_{L}$ for all three configurations using the measured mass flow. This demonstrates that the sweeping jets can achieve the same lift performance as the steady blowing configuration with $54.7 \%$ less mass flow and is consistent with the reduction in $\mathrm{C}_{\mu}$ shown in Figure 21.

The influence of angle-of-attack on the Actuator AA configuration is shown in Figure 24 at a Reynolds number of $10 \times 10^{6}$. The nonblowing case is compared to NPR=1.49 and 3.01 conditions. A nearly constant lift increment is observed for both blowing conditions over the entire angle-of-attack range, indicating robust performance of the actuators. Stall for the $30^{\circ}$ flap was not achieved as it was beyond the 28 degree limits of the angle-of-attack system as it was configured. The effect of actuator AA on the outboard wing pressure distribution is examined in Figure 25 at $\alpha=0^{\circ}$. Both configurations are at similar lift coefficient values, and the pressure distributions agree quite well. The steady blowing case has a higher suction peak at the flap crest, while the Actuator AA configuration has more suction downstream of the flap crest. Similar agreement was observed at the inboard wing stations.

Figure 26 compares the sweeping jet results for two Mach numbers to the steady blowing configurations from a previous FAST-MAC experiment described in Reference 25. The momentum for both Mach number configurations are similar but the blowing authority of the sweeping jet and steady blowing configuration at the lower Mach number results in a higher $\Delta \mathrm{C}_{\mathrm{L}}$. The momentum data from the Mach $=0.2$ condition is consistent with the mass flow reduction of 55\% shown in Figure 21. The steady blowing results at a Mach $=0.1$ are believed to be in the super-circulation regime showing a comparable mass flow reduction but with an $8 \%$ increase in lift compared to the Mach 0.2 condition.

\section{Sweeping jet configuration for the $60^{\circ}$ flap}

The final high-lift case examined was the $60^{\circ}$ flap configuration. The actuator-AA was used for the $60^{\circ}$ flap, as its higher mass flow characteristics would be advantageous for this challenging flap deflection. Figure 27 compares the sweeping jet results at a Mach $=0.2$ to a steady blowing case from the second FAST-MAC experiment described in Reference 25. The separation control regime for the steady blowing configuration ends at $\mathrm{C}_{\mu} \sim 0.040$ with a lift coefficient increment of 1.1. The sweeping jets only provided a lift increment of approximately $\Delta \mathrm{C}_{\mathrm{L}}$ of 0.10 because the flow was limited to a $\mathrm{C}_{\mu}=0.0045$ due to limits on the internal plenum pressure. This resulted in a small region of attached flow on the inboard portion of the flap. The flap pressures indicated that the three outboard rows separated at the crest of the flap, as if the sweeping jets were not present. Although the sweeping jets provided a minimal lift increment in this application, the small lift increment was observed to be consistent with the low blowing conditions of the steady blowing configuration. Further research is required to formulate a sweeping jet arrangement for such a challenging case.

\section{b. Transonic Cruise Results}

The flow physics encountered at the transonic conditions differ significantly from those in the low-speed regime discussed above. The flow is dominated by compressibility and the presences of shockwaves on the wing. Previous steady blowing results for the model indicated that the required jet-exit velocity needed to be at or above the freestream Mach number to influence the shockwave on the wing. The presence of shock-induced flow 
separation at off-design conditions further challenges the application of active flow control. These factors fed directly into the design of actuator AA, specifically maintaining sweep authority at supersonic NPR levels.

\section{Steady Blowing}

The transonic steady blowing results obtained during the third test of the FAST-MAC model (NTF Test 222), focused on evaluating numerous upgrades to the force and moment measurement system, aimed at improving the transonic drag repeatability at the mild cryogenic condition of $-50^{\circ} \mathrm{F}$. Reference 23 gives a detailed overview of the successful system-level engineering approach, which included a significant redesign of the Balance Cavity Recirculation System (BCRS) heating system, an improved pressure-tare balance calibration, and additional alignment pins in the high-pressure air/model-delivery interface. The model was configured with a fullspan nondimensional slot height of $\mathrm{h} / \mathrm{c}=0.0021$. The analysis for the repeat runs presented below indicated a $2 \sigma$ repeatability variation of the drag coefficient of $C_{D}= \pm 0.0003$.

The effect of the steady blowing on the wing pressures at an off-design Mach number of 0.88 are shown in Figure 28 at $\alpha=3^{\circ}$ and $\mathrm{Re}=30 \times 10^{6}$. The nonblowing result, NPR $=1.00$, indicates shock-induced flow separation on the outboard portion of the wing. The addition of blowing, NPR $=1.79$, has had a strong influence on the wing pressures, suggesting the flow has reattached downstream of the shockwave. The shock has moved aft $5 \%$ chord at $\eta=0.60$, and $10 \%$ chord at $\eta=0.80$, with little change in the shock strength. Figure 29 shows the effect of the steady blowing on the measured lift and drag coefficients. At the design lift coefficient of 0.50 , the drag was reduced by $6.5 \%$ ( 0.0025 or 25 counts $)$ for NPR $=1.78$ and $\mathrm{C}_{\mu}=0.00498$.

\section{Sweeping Jet Actuators}

The only sweeping jet cartridge evaluated during the current test was Actuator AA, as it was designed specifically for this flow regime. The success of the steady transonic blowing experiments had shown that the exit Mach number at the blowing slot needed to be at or above the freestream Mach number. It was also anticipated that reducing the blowing exit area by using the discrete sweeping jet cartridges would require that the local values of NPR across the wing would well exceed those used in the steady blowing. This was further reinforced by the lowspeed high-lift results that utilized NPR values around 3.00. The same model safety pressure limit for the sweeping jet cartridges was still applicable for the transonic cruise testing. This would ultimately have a limiting effect on the mass flow available to the model at the highest Reynolds number of $30 \times 10^{6}$ to be discussed below.

Figure 30 shows the effect of sweeping jet actuator AA on the attached-flow wing pressure distributions at $\mathrm{M}=0.85, \alpha=3^{\circ}$, and $\operatorname{Re}=15 \times 10^{6}$. The sweeping jets have had a slight influence on the shockwave upstream of the blowing slot, reducing the shock strength, followed by an accelerated flow over the upper flap surface. The lower surface has also been slightly affected by the sweeping jets, indicating a measurable increase in pressure, particularly near $\mathrm{x} / \mathrm{c}=0.35$. Figure 31 documents the effect of the sweeping jet actuators at two NPR values as the angle of attack is varied. At the design lift coefficient of 0.50 , the sweeping jets reduced the drag by $1.70 \%$ ( 0.00055 or 5.5 counts).

Figure 32 presents the effect of the sweeping jet actuator AA at the off-design condition of $\mathrm{M}=0.88, \alpha=3^{\circ}$, and $\operatorname{Re}=15 \times 10^{6}$. The nonblowing case $(\mathrm{NPR}=1.00)$ suggests shock-induced flow separation on the outboard portion of the wing $(\eta=0.80)$. The sweeping jets have had a noticeable effect on the wing pressures. At $\eta=0.60$ the shock has moved aft slightly, and the downstream pressure recovery has improved. At the outboard station $(\eta=$ 0.80 ), the shockwave has moved aft approximately $5 \%$ chord, while the downstream pressure recovery still indicates flow separation. As with the steady blowing case, the shockwave strength has not been altered. An infrared flow visualization technique was used in an attempt to quantify the influence of the sweeping jet cartridges on the flow, and document the extent of possible flow reattachment. The technique unfortunately was not successful, as the sensitivity of the optical glass was not well matched to the infrared camera available. Even though further research is necessary to appreciate the level of flow reattachment that may have occurred, the drag polar comparison in Figure 33 indicates that the sweeping jets have reduced the drag coefficient by $3.3 \%$ ( 0.0014 or 14 counts). Although the sweeping jets offer half the drag reduction shown for the steady blowing case (Figure 28), the sweeping jets accomplished this with an $80 \%$ reduction in mass flow.

The drag changes achieved with the sweeping jets at both Mach numbers are plotted as a function of the lift coefficient in Figure 34. The $2 \sigma$ values for the drag coefficient repeatability $\left(\Delta C_{D} \pm 0.0003\right)$ are shown for comparison. The NPR $=4.00$ condition offers a broader range of drag reduction, particularly at lift coefficients above 0.50 .

The last condition examined was increasing the Reynolds number to the realistic flight value of $30 \times 10^{6}$, as shown in the wing pressure comparison at $\mathrm{M}=0.88$ and $\alpha=3^{\circ}$ in Figure 35. To achieve this tunnel condition, the 
mild cryogenic condition of $-50^{\circ} \mathrm{F}$ was used, and a tunnel total pressure $50 \%$ higher than the $\operatorname{Re}_{\mathrm{C}}=15 \times 10^{6}$ results presented above. These elevated tunnel conditions coupled with the model pressure safety limit, reduced the mass flow that could be passed through the actuators, and thus the momentum coefficient $C_{\mu}$. Note that the $C_{\mu}$ value at $\operatorname{Re}_{C}=30 \times 10^{6}$ is similar to that shown at the lower Reynolds number in Figure 32. Due to this undesired reduction in available mass flow, the sweeping jet actuators were observed to have less influence on the shockwave, with the outboard station showing a more localized effect on the shock structure. The comparison of the drag polars in Figure 36 reveals that at the design lift coefficient of 0.50 , the sweeping jet actuators only reduced the drag by 0.0004 , just outside the $2 \sigma$ values of the drag coefficient repeatability $\left(\Delta \mathrm{C}_{\mathrm{D}} \pm 0.0003\right)$. Given the unexpected limitation of the available mass flow from the actuators, the influence of the flight Reynolds number on the sweeping jet actuator authority cannot be documented at this time. Increasing the throat area of the actuators would be recommended, to allow a more realistic variation of $\mathrm{C}_{\mu}$ for this high Reynolds number condition.

\section{Concluding Remarks}

The FAST-MAC wind tunnel model was modified to allow an array of thirty-nine sweeping jet actuators to be tested on both the high-lift and transonic cruise configurations, at high Reynolds numbers in the National Transonic Facility. Two types of sweeping jet actuators were evaluated. The first, actuator A, was a geometry with demonstrated performance when applied to simple-hinged flaps in high-lift mode. The second type, actuator AA, was a recent design for transonic conditions and maintains sweep authority at higher nozzle pressure ratios. The objective of the test was to compare the performance of the sweeping jet actuators in the separation control regime, to conventional steady blowing from the original open slot geometry. The following conclusions can be drawn from the research.

The actuator A sweeping jet cartridges were originally manufactured using a novel composite metallic/sandwich technique with electroplating bonding. The method provided high geometry fidelity for the small actuator sizes, but was prone to stress cracking and leaks, when the retention fasteners in the model were torqued. The cartridges were remanufactured using stereo lithography rapid prototype methods. This fabrication technique was also used for the actuator AA configuration. The stereo lithography technique provided robust cartridges that performed satisfactory over the entire testing envelope, including mild cryogenic conditions of $-50^{\circ} \mathrm{F}$, and transonic Mach numbers.

For the $30^{\circ}$ flap high-lift configuration, both sweeping jet actuators were capable of reattaching the flow on the simple-hinged flap, providing a lift increment comparable to the steady blowing configuration, while realizing a mass flow reduction of 54\%. The transonic cruise sweeping jet, actuator AA, offered a slight lift performance advantage over actuator $\mathrm{A}$, due to the increase in throat area and corresponding higher mass flow output. The wing pressures with actuator AA were found to be quite similar to the steady blowing result at a comparable lift coefficient. The sweeping jet actuators performed well over the entire angle-of-attack range, demonstrating consistent flow control authority.

The $60^{\circ}$ flap high-lift configuration was a significant challenge for the sweeping jet actuators. They were only able to attach the flow on the inboard flap, while the remainder of the flap remained separated, providing a small lift increment. Further research is needed for this large flap deflection.

In the transonic regime, the sweeping jets did demonstrate the ability to influence the flow over the wing at the intermediate Reynolds number of $15 \times 10^{6}$. At the design Mach number of 0.85 , and attached flow on the wing, the actuator AA slightly altered the shockwave on the outer portion of the wing, and accelerated the flow downstream of the sweeping jets. At the design lift coefficient of 0.50 , the drag was reduced by $1.70 \%$. At the off-design Mach number of 0.88 , shock induced flow separation occurs on the outboard portion of the wing at the same lift coefficient. The sweeping jets moved the shockwave aft $5 \%$ chord at the $80 \%$ semispan location, with no increase in shock strength. Even though the wing pressures still indicate flow separation at this station, the drag was reduced by $3.3 \%$. Although the sweeping jets offer only half the drag reduction shown for the steady blowing case (6.5\%), the sweeping jets accomplished this with a $74 \%$ reduction in mass flow.

As the transonic Reynolds number was increased to the realistic flight value of $30 \times 10^{6}$, the mass flow that could be passed through the sweeping jet actuators was limited by the model pressure safety limit, and the elevated tunnel total pressure. As a result, the available range of the mass flow was not adequate to allow the actuator authority to be properly documented at the flight Reynolds number. It is suggested that future testing should include variations in the throat area for the sweeping jet actuators to avoid this limitation. 


\section{Acknowledgements}

The research has been supported by the AATT project. Special thanks are given to Scott Anders, Sally Viken, Richard Wahls, and Susan Wilz for their continued support and enthusiasm. The successful testing of the FASTMAC model could not have been accomplished without the dedication, technical expertise, and energy of the entire staff at the National Transonic Facility. Special gratitude is extended to the Rob Andrews and the staff of the NASA LaRC rapid prototyping group for their continued support in fabricating the many different actuator concepts. 
Table 1. Actuator dimensions.

\begin{tabular}{|c|c|c|c|c|c|c|c|}
\hline \multirow[b]{2}{*}{ Actuator } & \multirow[b]{2}{*}{$h / c$} & \multicolumn{3}{|c|}{ ACTUATOR A } & \multicolumn{3}{|c|}{ ACTUATOR AA } \\
\hline & & $\begin{array}{c}\text { SPACING = } \\
\Delta \text { CENTER/ } \\
\text { EXIT WIDTH }\end{array}$ & $\begin{array}{l}\text { INDIVIDUAL } \\
\text { THROAT } \\
\text { AREA }\left(\text { in }^{2}\right)\end{array}$ & $\begin{array}{c}\text { INDIVIDUAL } \\
\text { EXIT AREA } \\
\left(\text { in }^{2}\right)\end{array}$ & $\begin{array}{c}\text { SPACING = } \\
\Delta \text { CENTER/ } \\
\text { EXIT WIDTH }\end{array}$ & $\begin{array}{c}\text { INDIVIDUAL } \\
\text { THROAT } \\
\text { AREA }\left(\mathrm{in}^{2}\right)\end{array}$ & $\begin{array}{l}\text { INDIVIDUAL } \\
\text { EXIT AREA } \\
\left(\mathrm{in}^{2}\right)\end{array}$ \\
\hline $1-2$ & 0.0029 & - & 0.0095 & 0.0631 & - & 0.0154 & 0.0504 \\
\hline $1-3$ & 0.0028 & 1.6257 & 0.0091 & 0.0618 & 1.8030 & 0.0154 & 0.0493 \\
\hline $1-4$ & 0.0028 & 1.2295 & 0.0087 & 0.0603 & 1.3636 & 0.0154 & 0.0481 \\
\hline $1-5$ & 0.0028 & 1.5770 & 0.0083 & 0.0590 & 1.7491 & 0.0154 & 0.0470 \\
\hline $1-6$ & 0.0028 & 1.2295 & 0.0079 & 0.0576 & 1.3636 & 0.0154 & 0.0459 \\
\hline $1-7$ & 0.0028 & 1.6678 & 0.0075 & 0.0562 & 1.8724 & 0.0150 & 0.0442 \\
\hline $1-8$ & 0.0028 & 1.2633 & 0.0072 & 0.0533 & 1.4151 & 0.0143 & 0.0422 \\
\hline $2-1$ & 0.0028 & 2.2027 & 0.0068 & 0.0475 & 2.6150 & 0.0107 & 0.0354 \\
\hline $2-2$ & 0.0027 & 1.6736 & 0.0064 & 0.0462 & 1.9869 & 0.0107 & 0.0345 \\
\hline $2-3$ & 0.0027 & 1.6724 & 0.0060 & 0.0448 & 1.9854 & 0.0107 & 0.0335 \\
\hline $2-4$ & 0.0027 & 1.5385 & 0.0057 & 0.0424 & 1.7817 & 0.0107 & 0.0325 \\
\hline $2-5$ & 0.0027 & 1.7568 & 0.0053 & 0.0396 & 1.9578 & 0.0107 & 0.0315 \\
\hline $2-6$ & 0.0026 & 1.6644 & 0.0050 & 0.0374 & 1.8662 & 0.0100 & 0.0295 \\
\hline $2-7$ & 0.0026 & 1.8425 & 0.0047 & 0.0349 & 2.0638 & 0.0094 & 0.0276 \\
\hline $2-8$ & 0.0026 & 2.0195 & 0.0044 & 0.0326 & 2.2605 & 0.0088 & 0.0258 \\
\hline $3-1$ & 0.0026 & 2.5667 & 0.0041 & 0.0269 & 2.8814 & 0.0064 & 0.0212 \\
\hline $3-2$ & 0.0026 & 1.4156 & 0.0039 & 0.0258 & 1.5556 & 0.0064 & 0.0208 \\
\hline $3-3$ & 0.0025 & 1.4156 & 0.0037 & 0.0251 & 1.5556 & 0.0064 & 0.0203 \\
\hline $3-4$ & 0.0025 & 1.8680 & 0.0035 & 0.0242 & 2.0207 & 0.0064 & 0.0198 \\
\hline $3-5$ & 0.0025 & 1.3128 & 0.0034 & 0.0234 & 1.4124 & 0.0064 & 0.0193 \\
\hline $3-6$ & 0.0025 & 1.2807 & 0.0032 & 0.0234 & 1.4124 & 0.0064 & 0.0188 \\
\hline $3-7$ & 0.0025 & 1.8204 & 0.0032 & 0.0234 & 2.0075 & 0.0064 & 0.0188 \\
\hline $3-8$ & 0.0026 & 1.2807 & 0.0032 & 0.0234 & 1.4124 & 0.0064 & 0.0188 \\
\hline $3-9$ & 0.0026 & 1.2807 & 0.0032 & 0.0234 & 1.4124 & 0.0064 & 0.0188 \\
\hline $3-10$ & 0.0027 & 1.8340 & 0.0032 & 0.0234 & 2.0226 & 0.0064 & 0.0188 \\
\hline $3-11$ & 0.0027 & 1.4156 & 0.0032 & 0.0234 & 1.5612 & 0.0064 & 0.0188 \\
\hline 3-12 & 0.0028 & 1.4156 & 0.0032 & 0.0234 & 1.5612 & 0.0064 & 0.0188 \\
\hline 4-1 & 0.0029 & 2.3941 & 0.0032 & 0.0234 & 2.6403 & 0.0064 & 0.0188 \\
\hline 4-2 & 0.0029 & 1.4105 & 0.0032 & 0.0234 & 1.5556 & 0.0064 & 0.0188 \\
\hline $4-3$ & 0.0030 & 1.4105 & 0.0032 & 0.0234 & 1.5556 & 0.0064 & 0.0188 \\
\hline $4-4$ & 0.0031 & 1.8289 & 0.0032 & 0.0234 & 2.0169 & 0.0064 & 0.0188 \\
\hline $4-5$ & 0.0031 & 1.2807 & 0.0032 & 0.0234 & 1.4124 & 0.0064 & 0.0188 \\
\hline 4-6 & 0.0032 & 1.2807 & 0.0032 & 0.0234 & 1.4124 & 0.0064 & 0.0188 \\
\hline 4-7 & 0.0033 & 1.8255 & 0.0032 & 0.0234 & 2.0132 & 0.0064 & 0.0188 \\
\hline $4-8$ & 0.0033 & 1.2807 & 0.0032 & 0.0234 & 1.4124 & 0.0064 & 0.0188 \\
\hline $4-9$ & 0.0034 & 1.2807 & 0.0032 & 0.0234 & 1.4124 & 0.0064 & 0.0188 \\
\hline 4-10 & 0.0035 & 1.8357 & 0.0032 & 0.0234 & 2.0245 & 0.0064 & 0.0188 \\
\hline 4-11 & 0.0036 & 1.4003 & 0.0032 & 0.0234 & 1.5443 & 0.0064 & 0.0188 \\
\hline 4-12 & 0.0037 & 1.4003 & 0.0032 & 0.0234 & 1.5443 & 0.0064 & 0.0188 \\
\hline
\end{tabular}

\begin{tabular}{|c|c|c|c|c|c|}
\cline { 2 - 6 } \multicolumn{1}{c|}{} & $\begin{array}{c}\text { TOTAL } \\
\text { THROAT } \\
\text { AREA (A) }\end{array}$ & $\begin{array}{c}\text { TOTAL EXIT } \\
\text { AREA (A) }\end{array}$ & $\begin{array}{c}\text { TOTAL } \\
\text { THROAT } \\
\text { AREA (AA) }\end{array}$ & $\begin{array}{c}\text { TOTAL EXIT } \\
\text { AREA (AA) }\end{array}$ & $\begin{array}{c}\text { AVERAGE } \\
\text { h/c }\end{array}$ \\
\cline { 2 - 6 } & 0.1820 & 1.3070 & 0.3417 & 1.0357 & 0.00285 \\
\hline FLOW PATH 1 & $\mathbf{0 . 0 5 8 3}$ & $\mathbf{0 . 4 1 1 3}$ & $\mathbf{0 . 1 0 6 5}$ & 0.3270 & $\mathbf{0 . 0 0 2 8 1}$ \\
\hline FLOW PATH 2 & $\mathbf{0 . 0 4 4 3}$ & $\mathbf{0 . 3 2 5 2}$ & $\mathbf{0 . 0 8 1 6}$ & $\mathbf{0 . 2 5 0 2}$ & $\mathbf{0 . 0 0 2 6 8}$ \\
\hline FLOW PATH 3 & $\mathbf{0 . 0 4 1 0}$ & $\mathbf{0 . 2 8 9 5}$ & $\mathbf{0 . 0 7 6 8}$ & $\mathbf{0 . 2 3 2 9}$ & $\mathbf{0 . 0 0 2 5 9}$ \\
\hline FLOW PATH 4 & $\mathbf{0 . 0 3 8 4}$ & $\mathbf{0 . 2 8 1 1}$ & $\mathbf{0 . 0 7 6 8}$ & $\mathbf{0 . 2 2 5 6}$ & $\mathbf{0 . 0 0 3 2 3}$ \\
\hline
\end{tabular}

Table 2. NTF SMSS Balance Loads.

\section{Component NTF 1175}

\begin{tabular}{|c|c|}
\hline Normal Force Ibs (N) & $12,000(53,379)$ \\
\hline Axial Force lbs (N) & $1,800(8,007)$ \\
\hline Pitching Moment Ibs-in (N-m) & $90,000(10,169)$ \\
\hline Rolling Moment Ibs-in (N-m) & $669,000(7,558)$ \\
\hline Yawing Moment Ibs-in (N-m) & $100,350(11,338)$ \\
\hline
\end{tabular}

American Institute of Aeronautics and Astronautics 


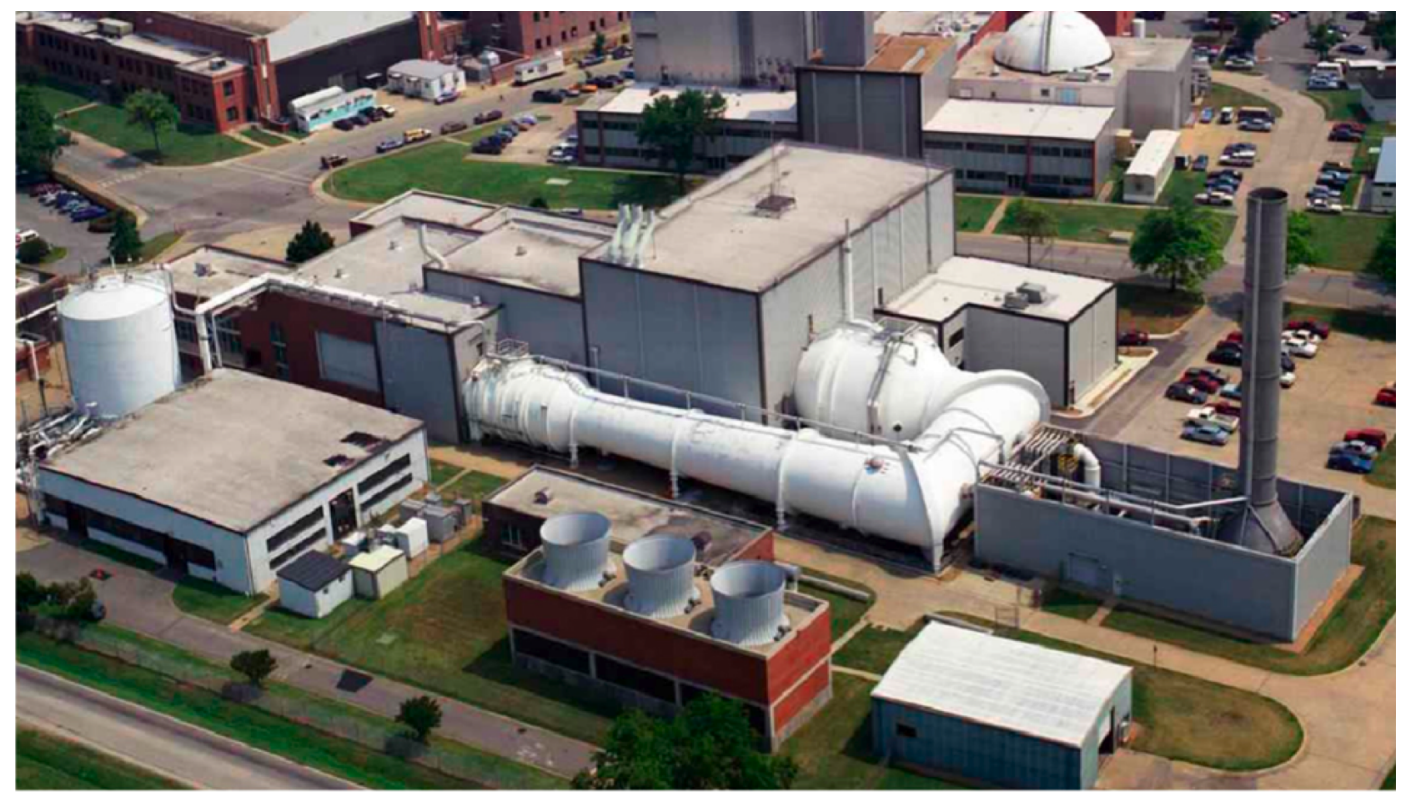

Figure 1. Aerial Photo of NASA Langley National Transonic Facility.

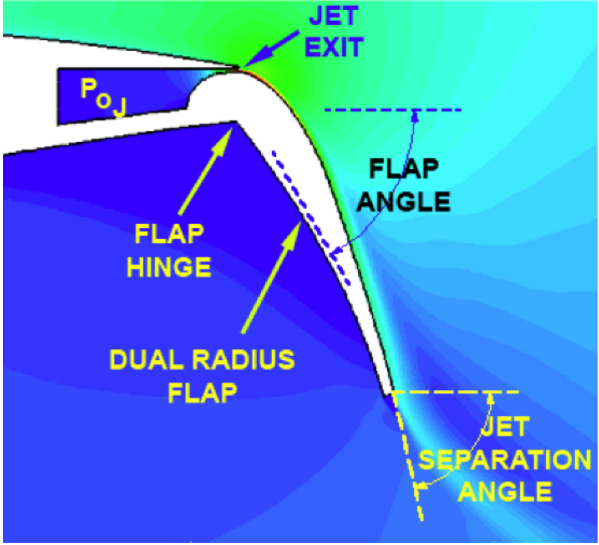

Figure 2. Circulation control blowing slot nomenclature.

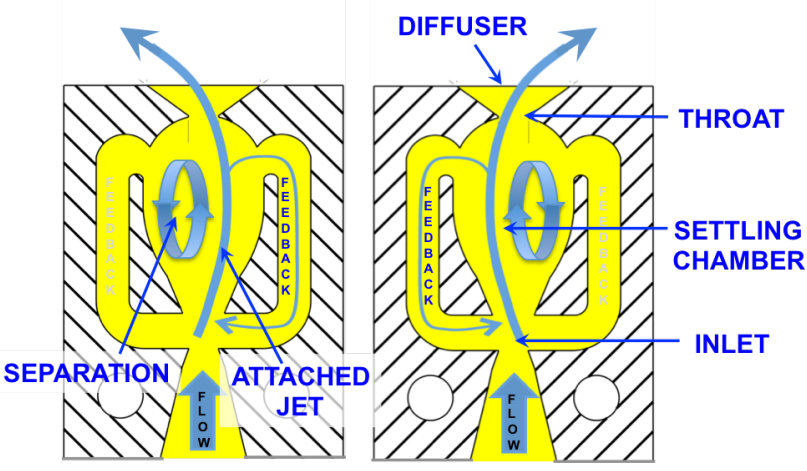

Figure 3. Fundamental characteristics of a sweeping jet illustrating the two extremes of the jet position and the feedback passages that drive the oscillatory motion. 


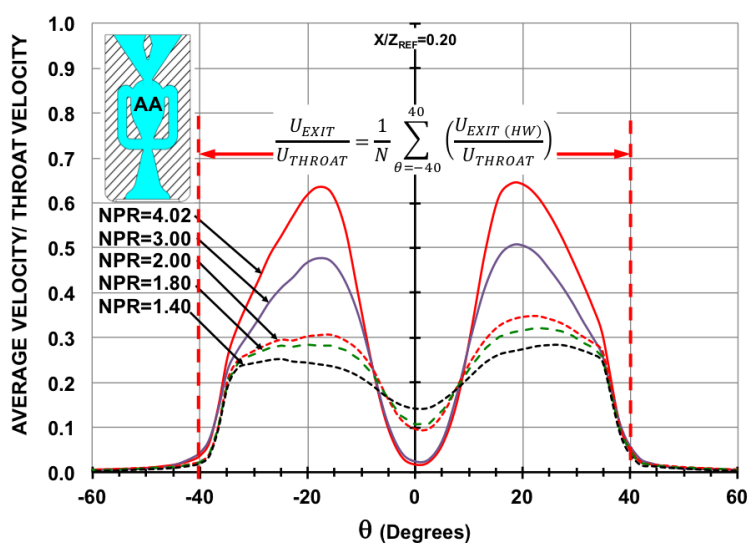

(a) THROAT: 0.080"x0.080" EXIT Y: 0.040", $\theta= \pm 35.5^{\circ}$

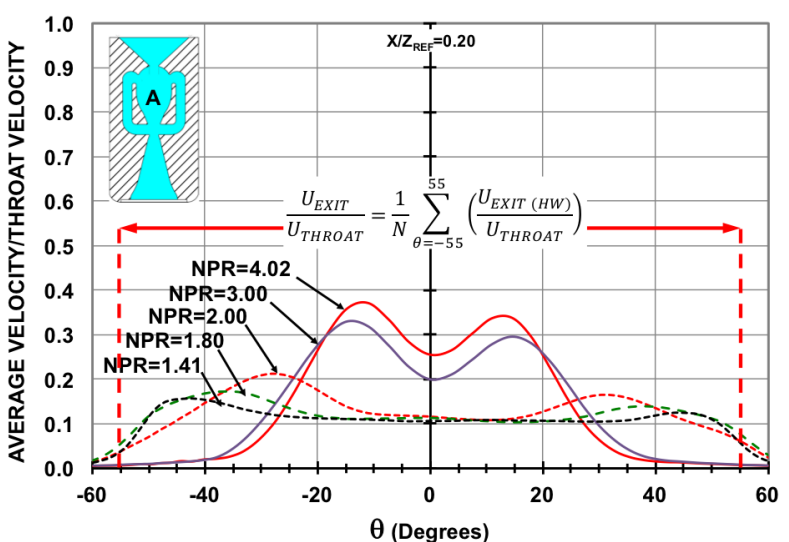

(b) THROAT: 0.040"x0.080" EXIT Y: 0.040", ", $\theta= \pm 45^{\circ}$

Figure 4. Hot wire comparison of performance of single actuators $A A$ and $A$ at actuator exit.

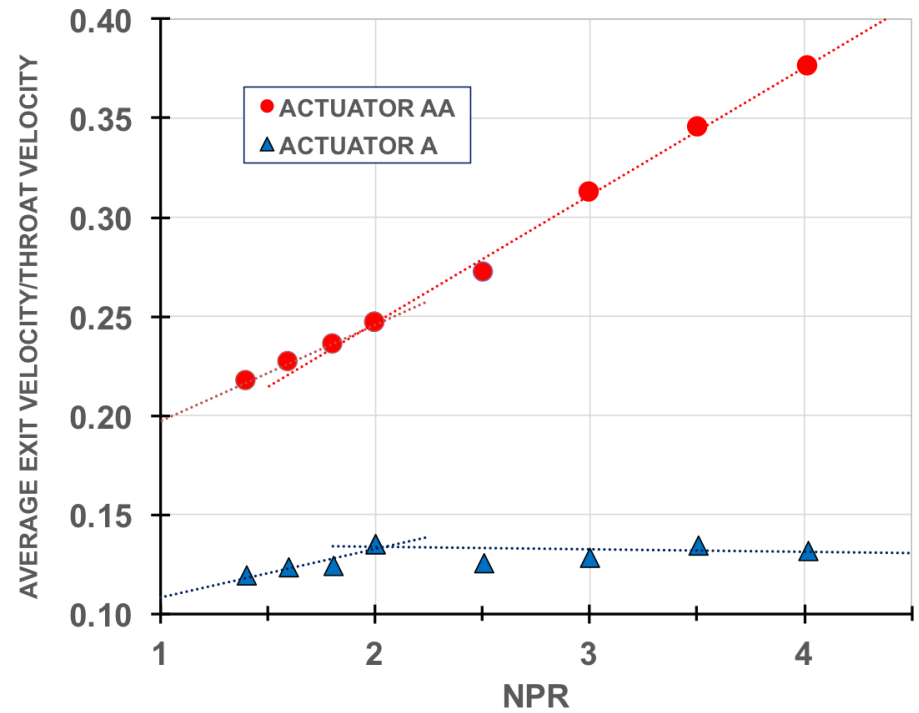

Figure 5. Average jet-exit velocity ratio for single actuators AA and $A$ measured along the span of the actuator.
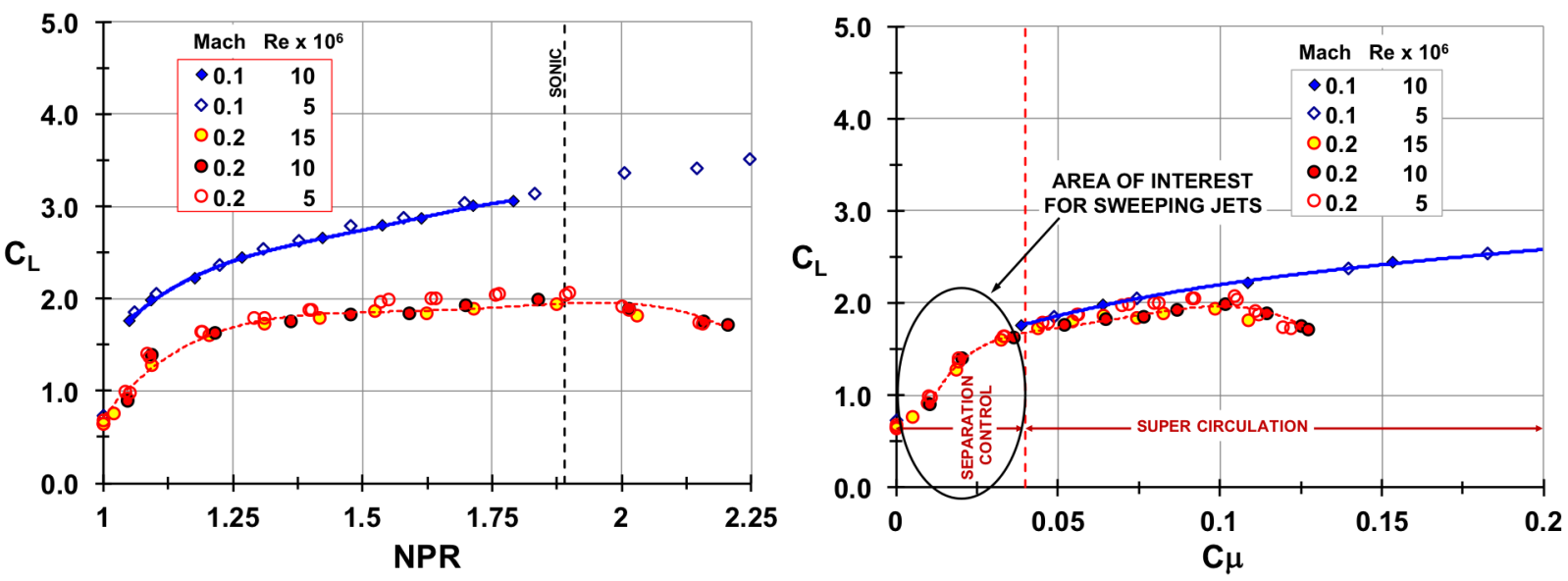

Figure 6. FAST-MAC high-lift performance for steady blowing at $60^{\circ}$ flap deflection, $\alpha=0^{\circ}$, open symbols: $\mathbf{h} / \mathrm{c}=\mathbf{0 . 0 0 3 3}$, closed symbols: $\mathrm{h} / \mathrm{c}=\mathbf{0 . 0 0 2 2}$. 


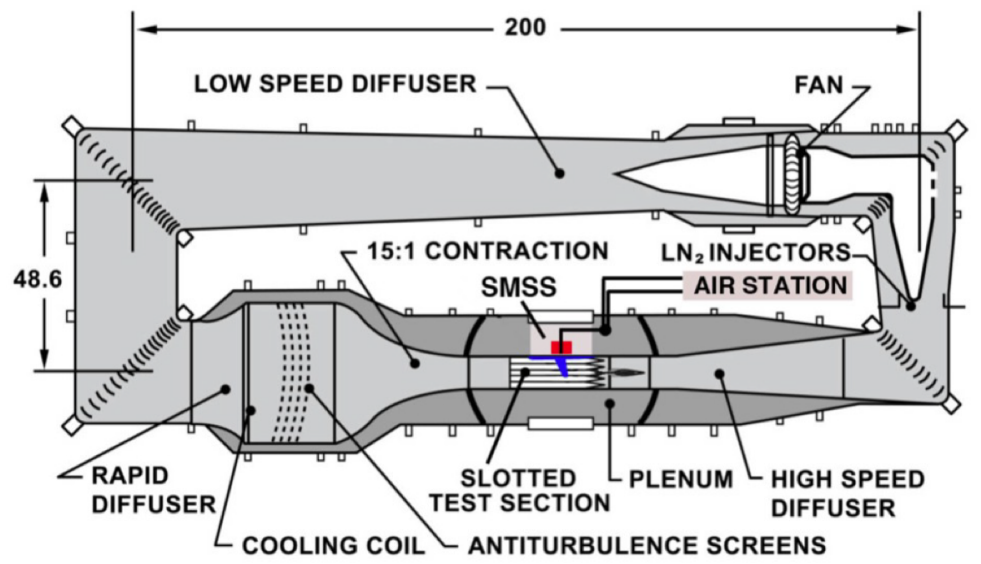

Figure 7. Sketch of the NTF highlighting the location of the SMSS

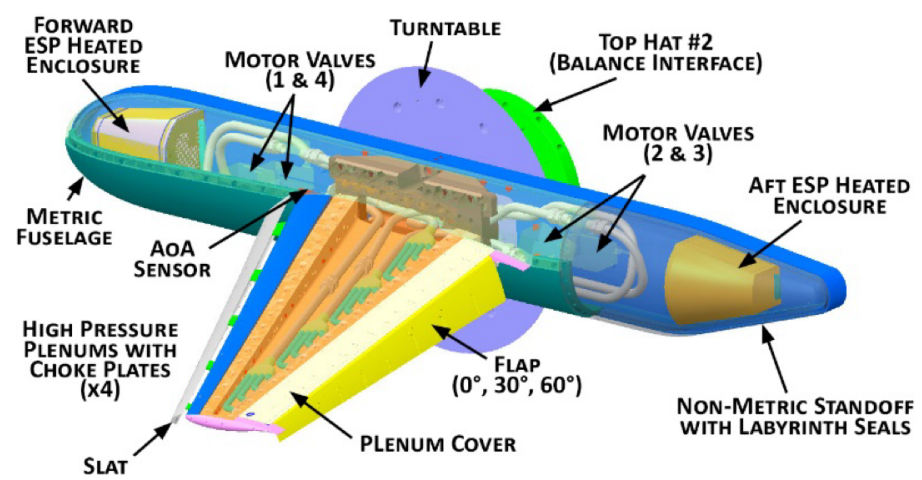

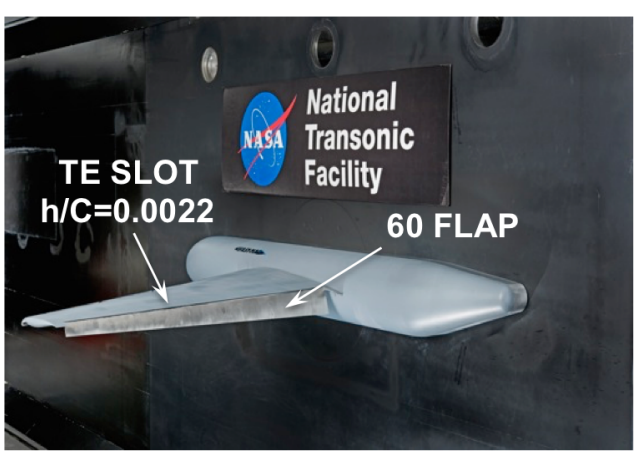

Figure 8. FAST-MAC model mounted in the NTF test section.

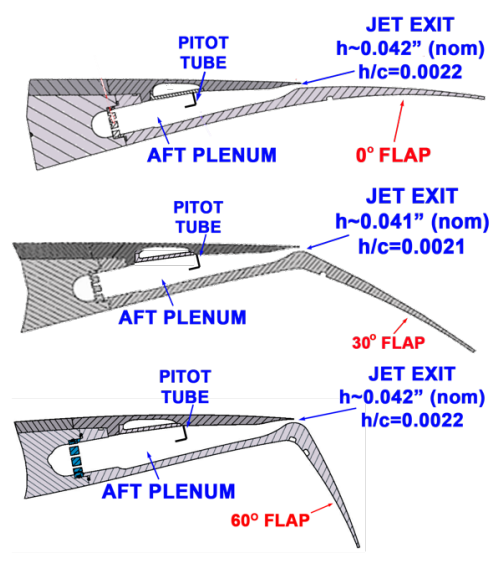

Figure 9. Cutaway view of the FAST-MAC model in high-lift mode, highlighting multiple flow paths and different flap configurations.

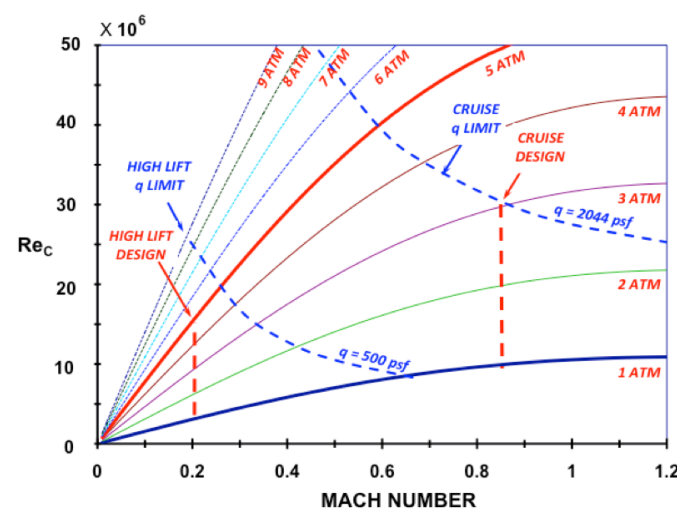

Figure 10. NTF operating envelope for FAST-MAC, $\mathrm{To}=-\mathbf{5 0}{ }^{\circ} \mathrm{F}, \mathrm{MAC}=19.4$ inches.

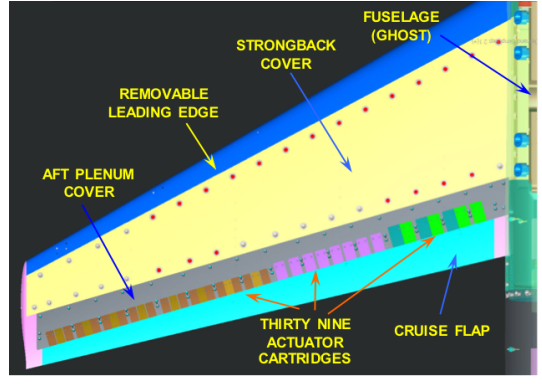

(a) Orientation of the sweeping jet actuator cartridges

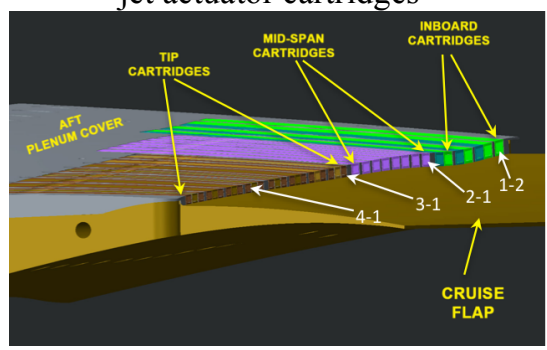

(b) Side view of the sweeping jet actuator cartridges

Figure 11. FAST-MAC actuator locations.
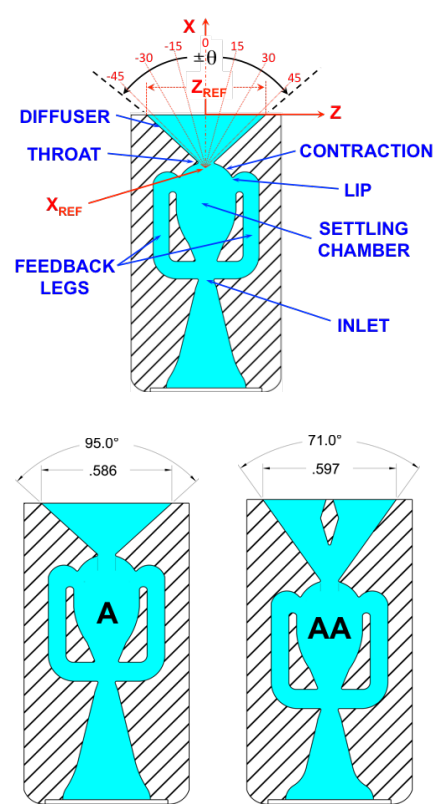

Throat:

Throat: $0.04 " \mathrm{x} 0.08 " \quad 0.08$ " 0.08 "

Figure 12. Actuator geometry. 

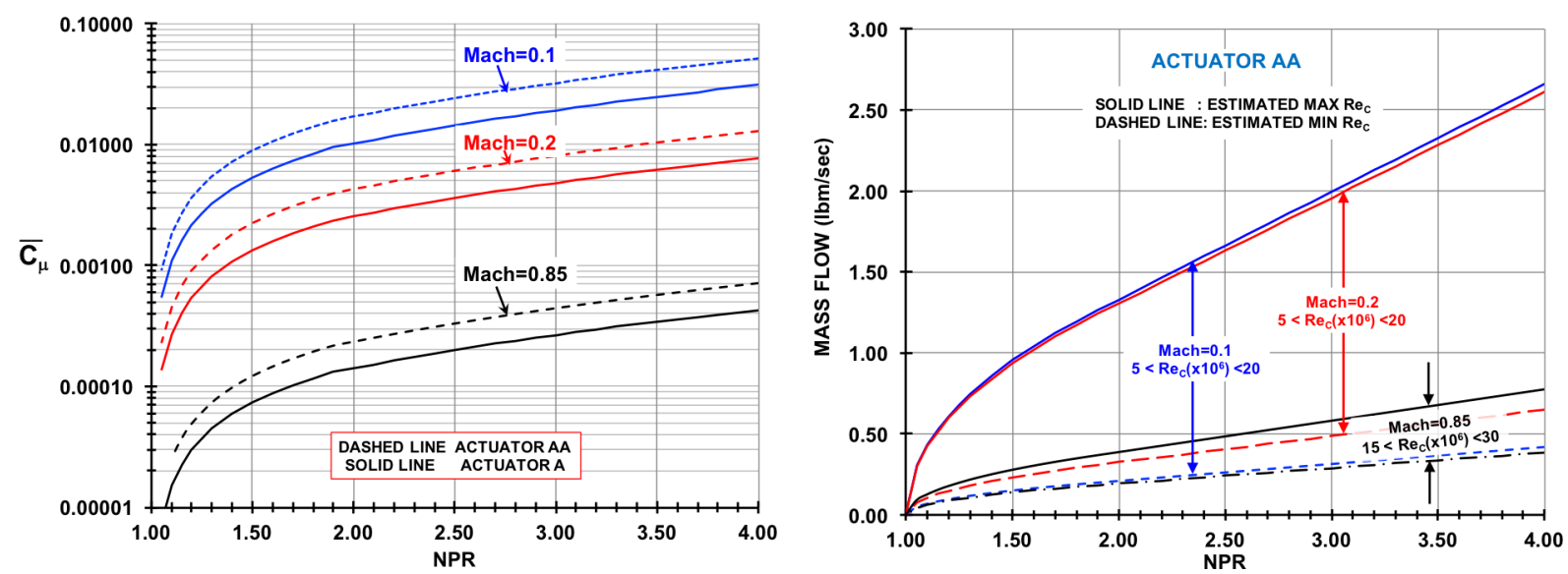

Figure 13. Ideal mass flow characteristics for sweeping jet actuators at high-lift and cruise conditions.

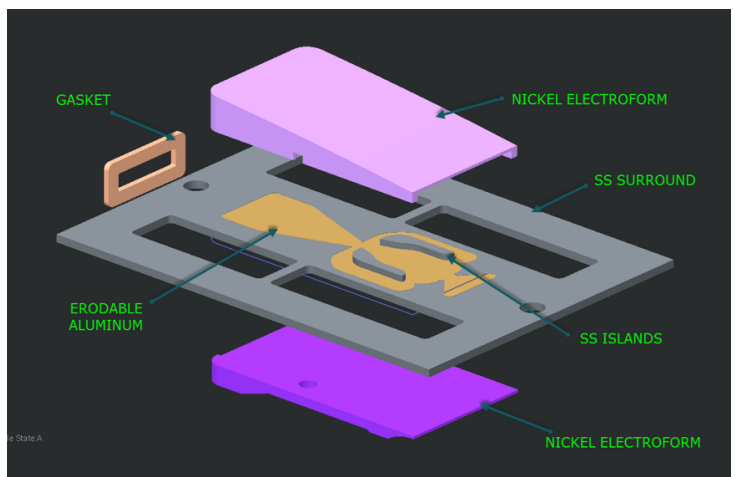

Figure 14. Expanded view of the plating configuration for the sweeping jet cartridge.

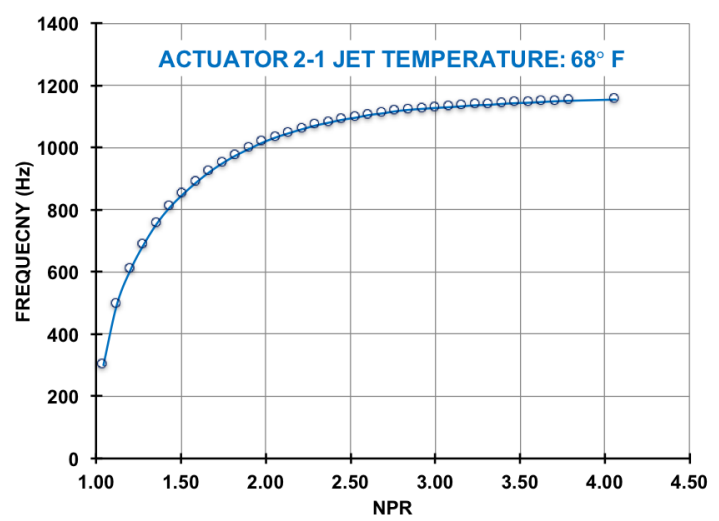

Figure 16. Frequency response of Actuator A (Size: 2-1) at ambient temperature.

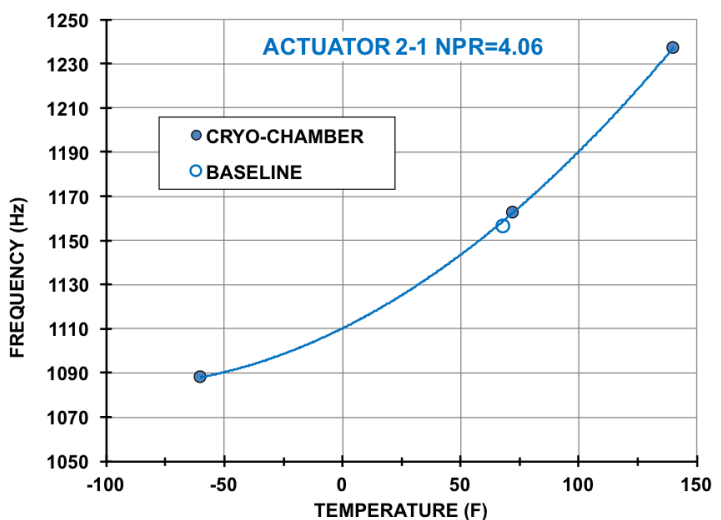

Figure 15. Temperature effect on Actuator A (Size: 2-1) at NPR 4.06.

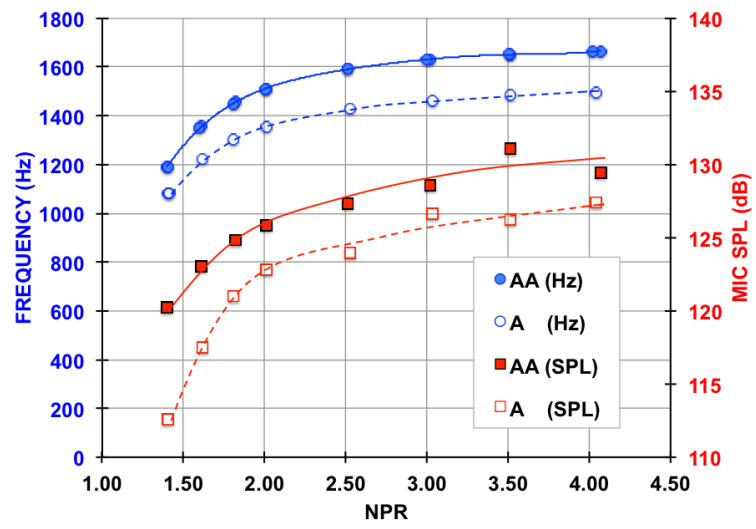

Figure 17. Sweeping jet peak frequency and corresponding SPL for actuators A and AA (Size: 4-1). 


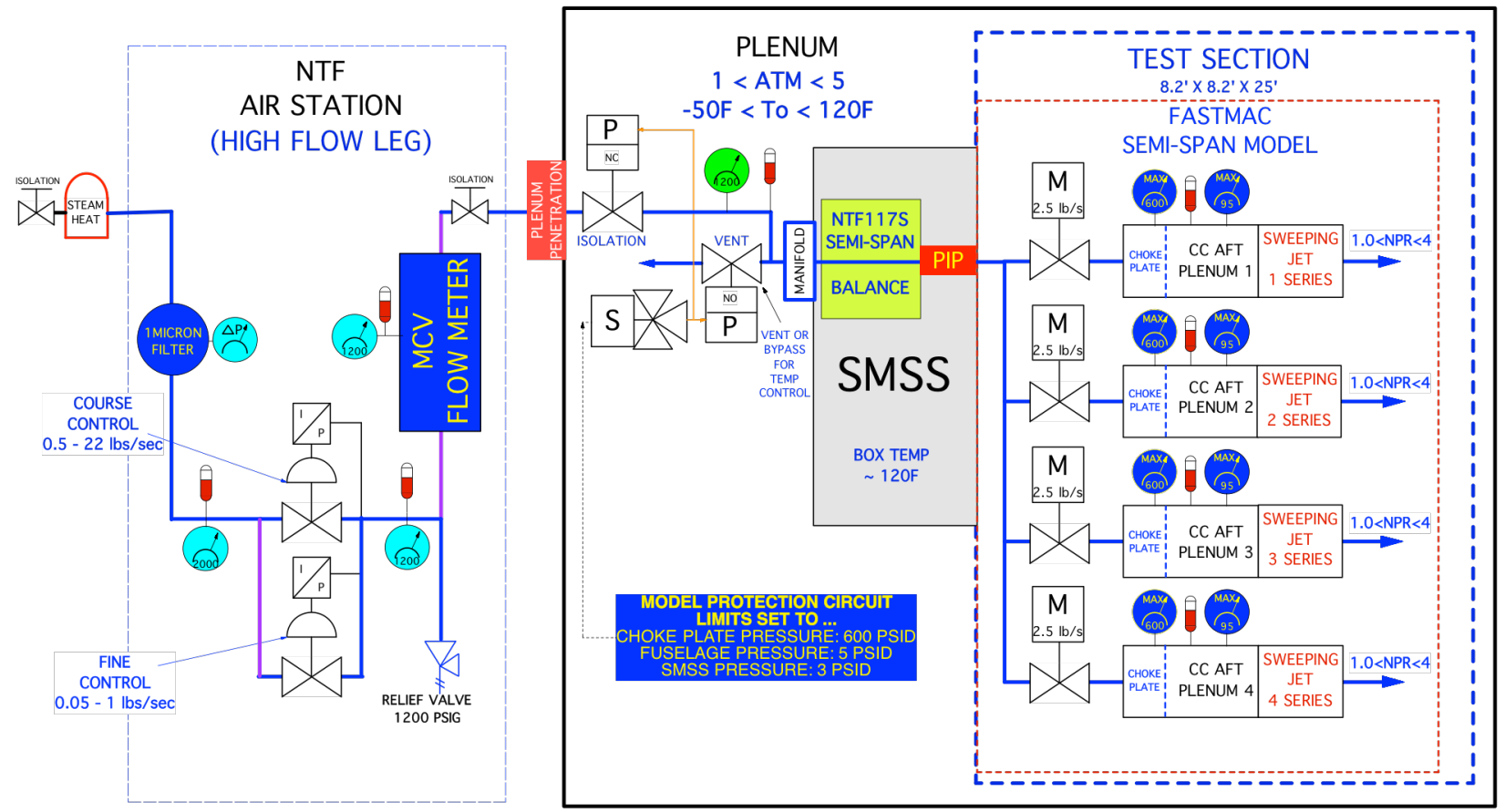

Figure 18. Schematic of the air delivery system for FAST-MAC with Sweeping Jets.

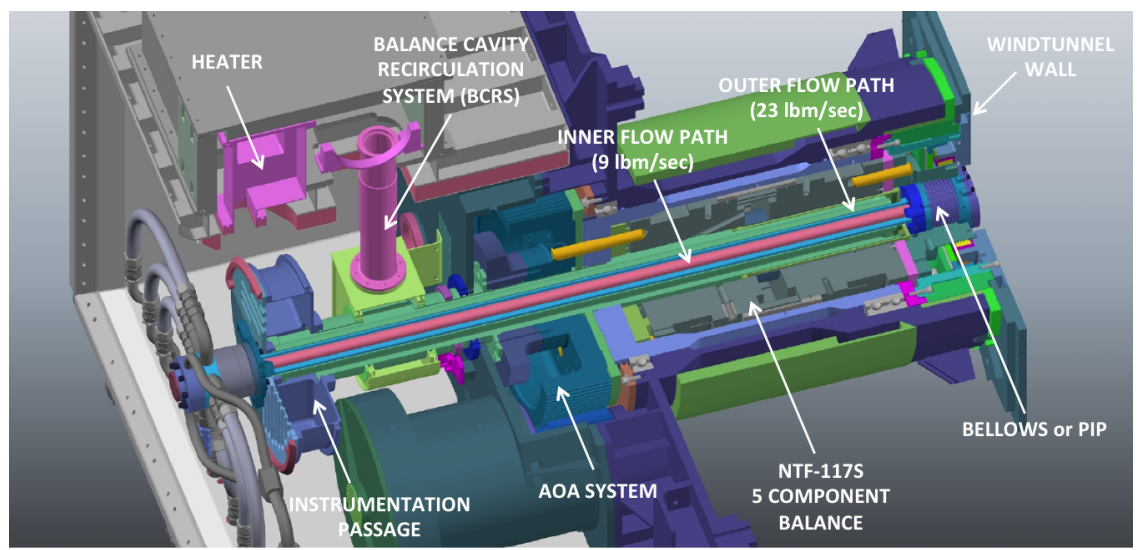

Figure 19. Cutaway sketch of the NTF SMSS highlighting the balance and co-annular flow path.
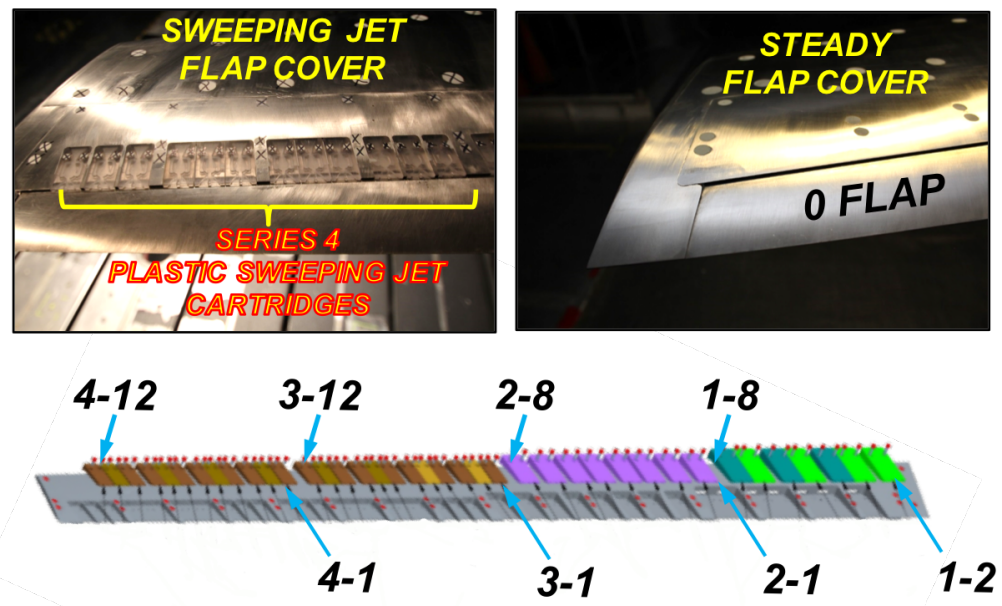

Figure 20. Actuator flap cover geometry highlighting the sweeping jet cartridge concept. 


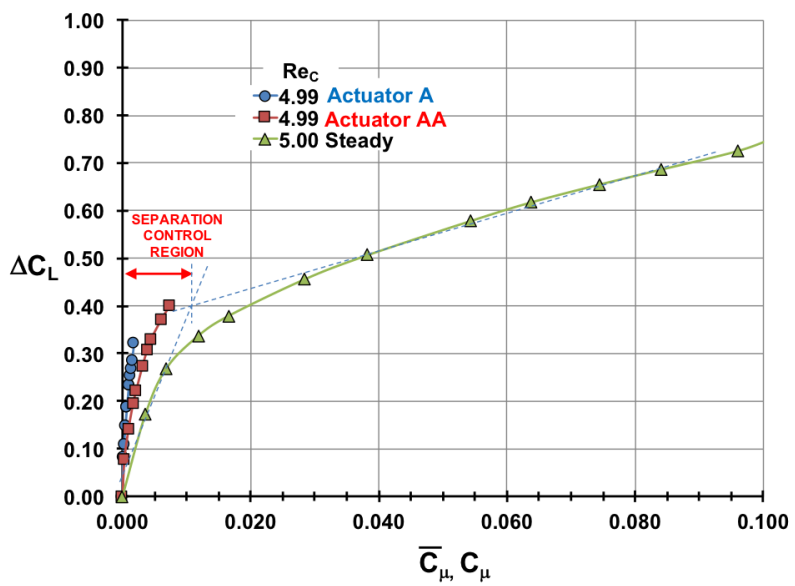

Figure 21. Comparison of lift performance of two sweeping jet configurations with the steady blowing configuration for different momentum coefficients for the $30^{\circ}$ flap deflection, $\alpha=0^{\circ}$, Mach $=0.2$.

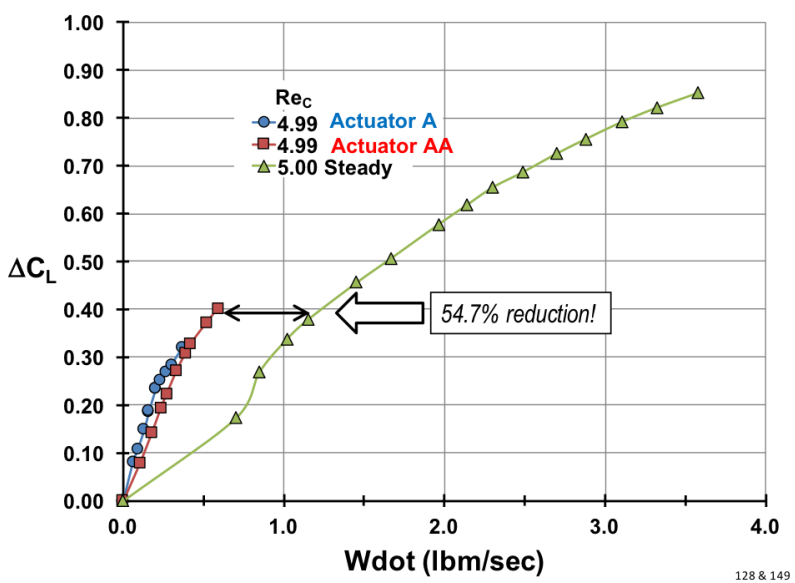

Figure 23. Mass flow reduction of sweeping jets compared to steady blowing, $30^{\circ}$ flap deflection, $\alpha=0^{\circ}, \operatorname{Mach}=0.2$.

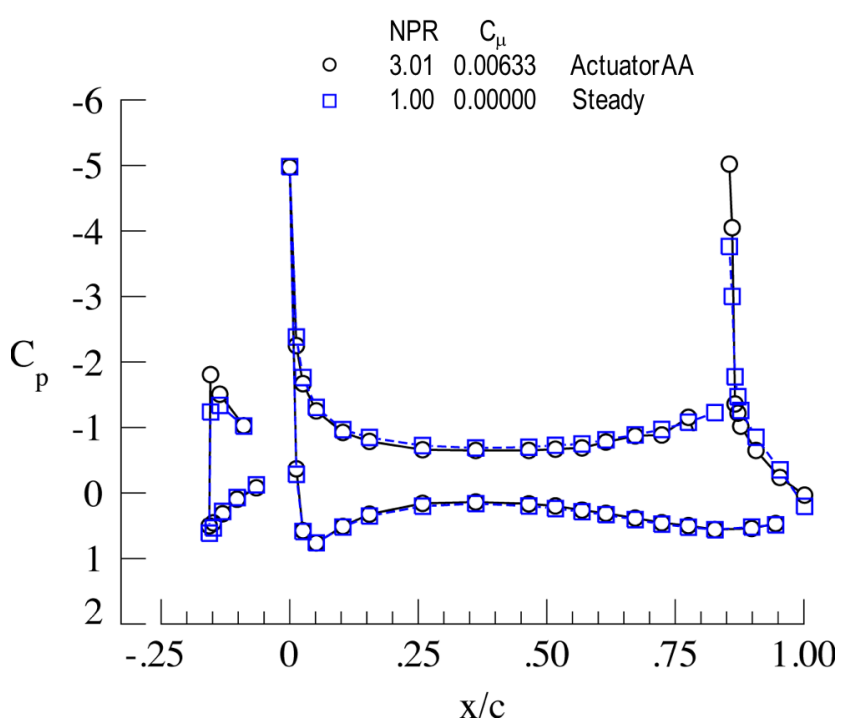

Figure 25. Wing pressures for steady blowing and sweeping jet blowing, Actuator $\mathrm{AA}, \mathbf{3 0}^{\circ}$ flap deflection, $\alpha=0^{0}, \eta=0.8, \operatorname{Mach}=0.2, \operatorname{Re}_{C}=5 \times 10^{6}$.

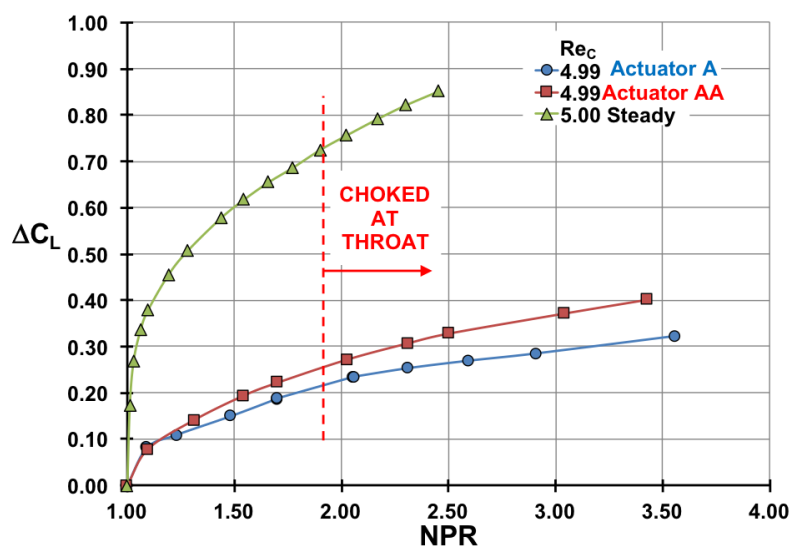

Figure 22. Comparison of lift performance of two sweeping jet configurations with the steady blowing configuration for different NPRs, $\mathbf{3 0}^{\circ}$ flap deflection, $\alpha=0^{\circ}$, Mach $=0.2$.

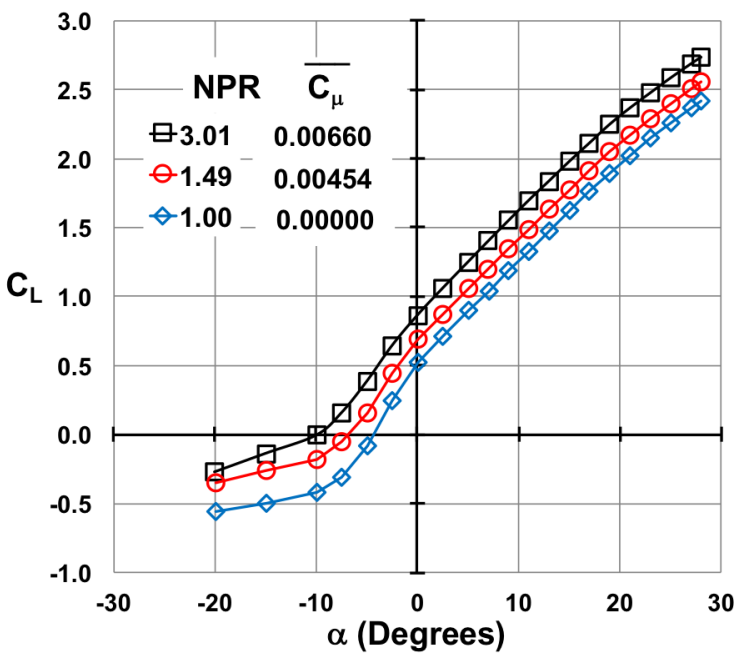

Figure 24. Comparison of sweeping jet blowing (Actuator AA) with baseline, $30^{\circ}$ flap deflection, $\operatorname{Mach}=0.2, \operatorname{Re}_{C}=10 \times 10^{6}$.

American Institute of Aeronautics and Astronautics 


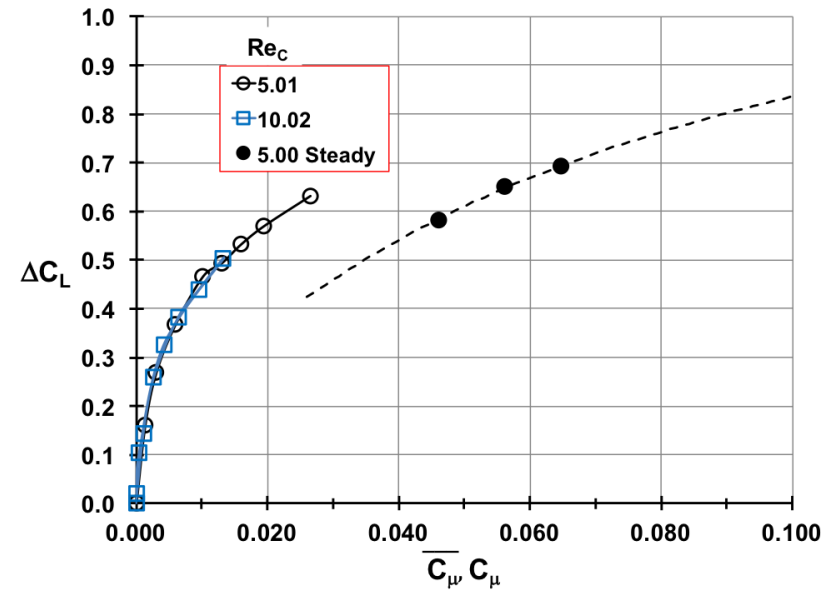

Mach $=0.1$

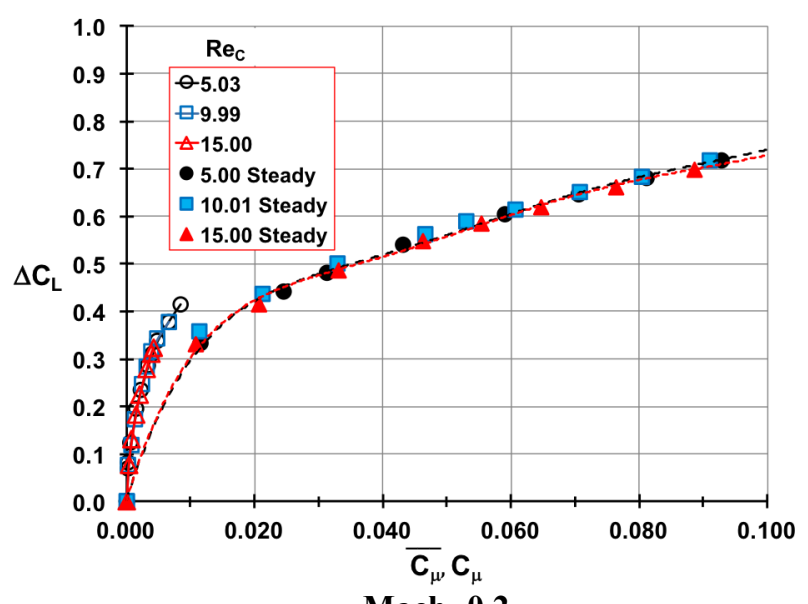

$\operatorname{Mach}=0.2$

Figure 26. Comparison of sweeping jet and steady blowing performance at different Reynolds numbers, $3^{\circ}$ flap deflection, at $\alpha=0^{\circ}$.

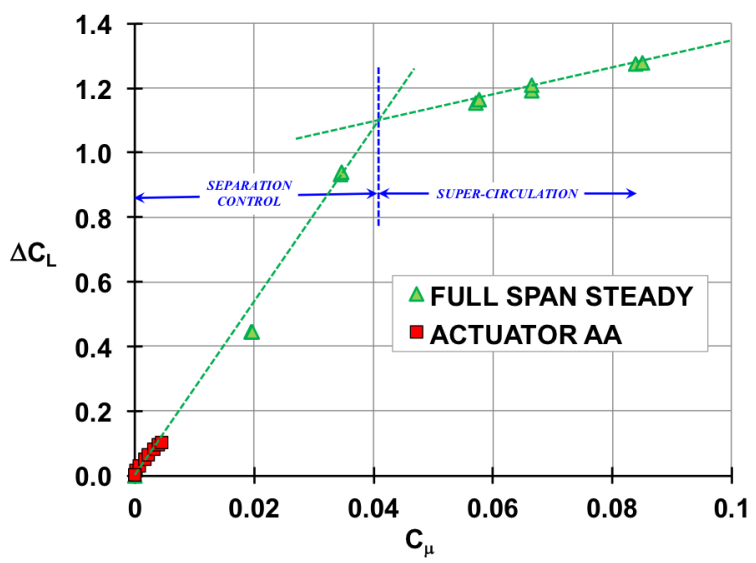

Figure 27. Comparison of sweeping jet blowing (Actuator AA) with baseline, $\mathbf{6 0}^{\circ}$ flap deflection, $M a c h=0.2, \operatorname{Re}_{C}=10 \times 10^{6}$.

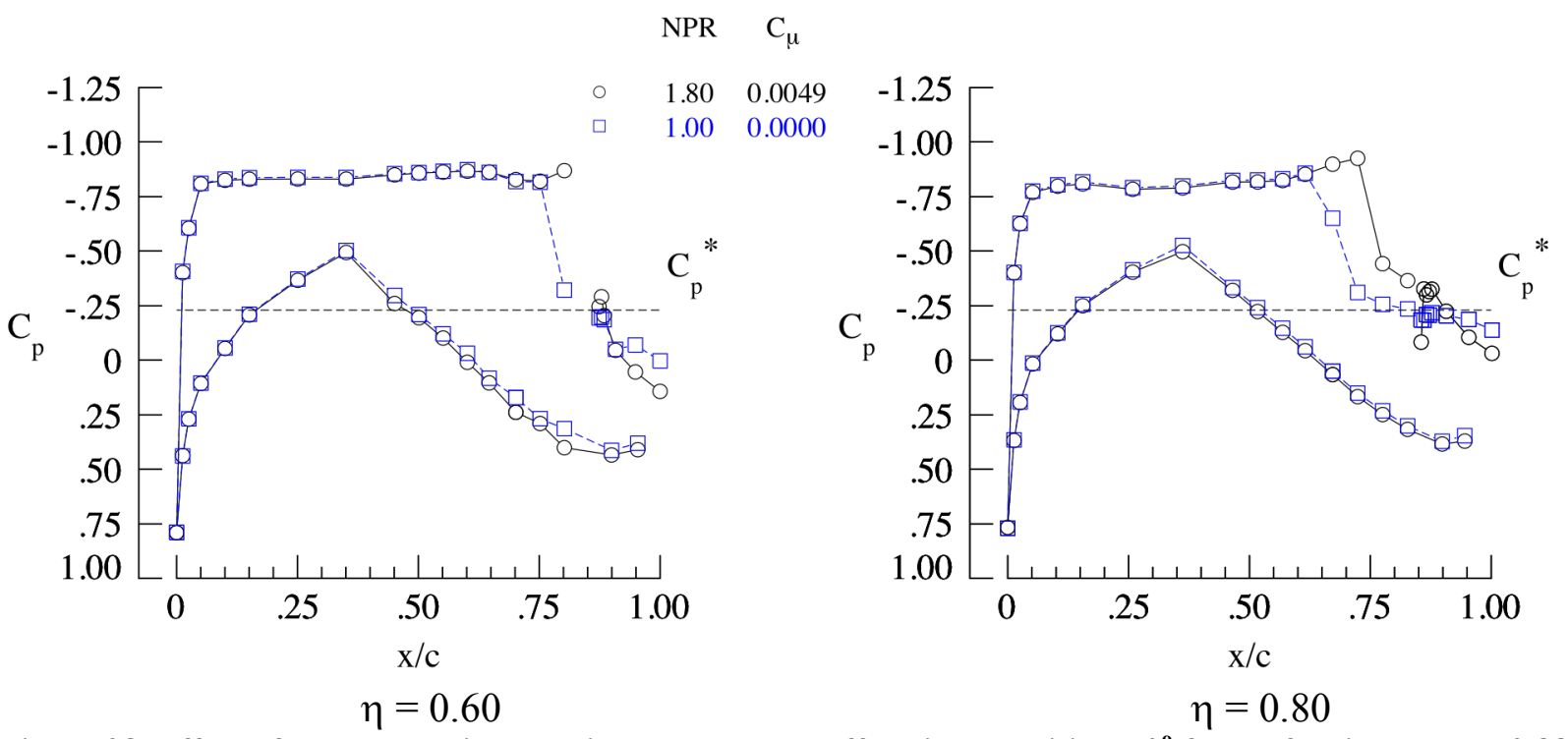

Figure 28. Effect of steady blowing on wing pressures at off-design conditions, $0^{\circ}$ flap deflection, Mach $=0.88$, $\alpha=3^{0}, \operatorname{Re}_{\mathrm{C}}=30 \times 10^{6}$. 


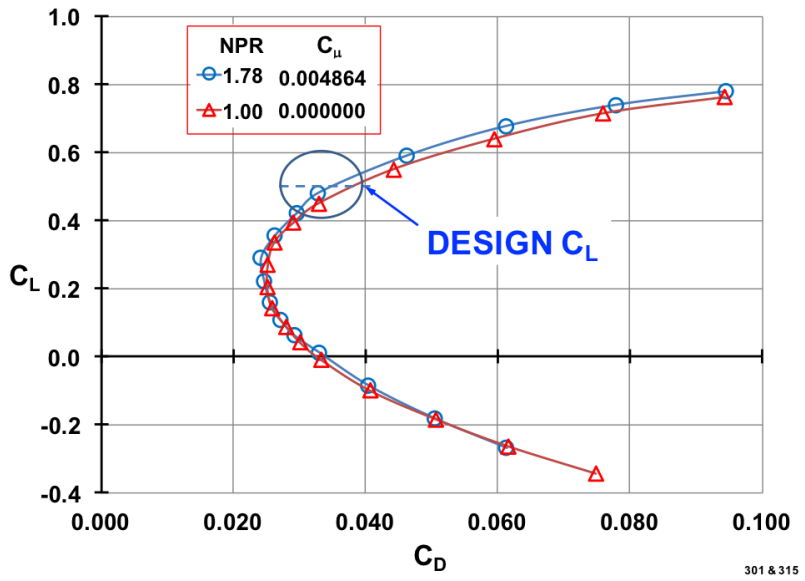

a. Polar

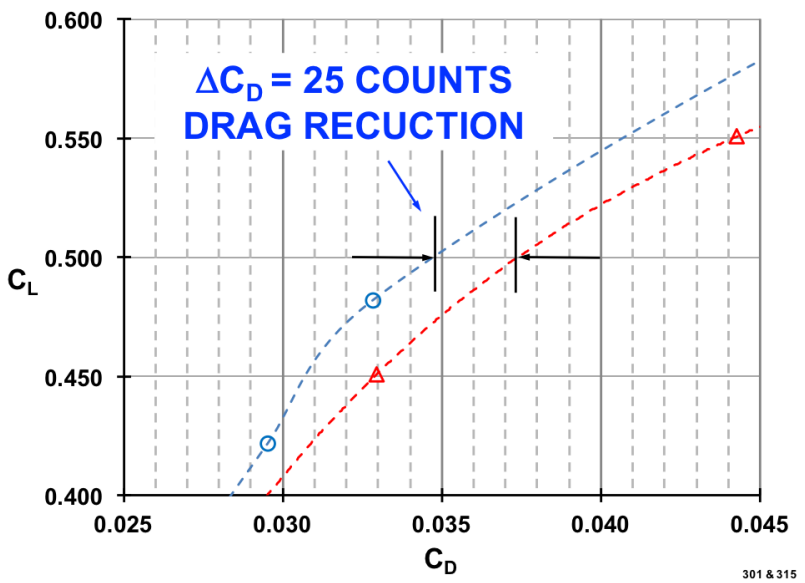

b. Zoomed on Design $C_{L}$

Figure 29. Drag improvement using steady blowing, $0^{0}$ Flap $\operatorname{Mach}=0.88, \alpha=3^{0}, \operatorname{Re}_{C}=30 \times 10^{6}$.

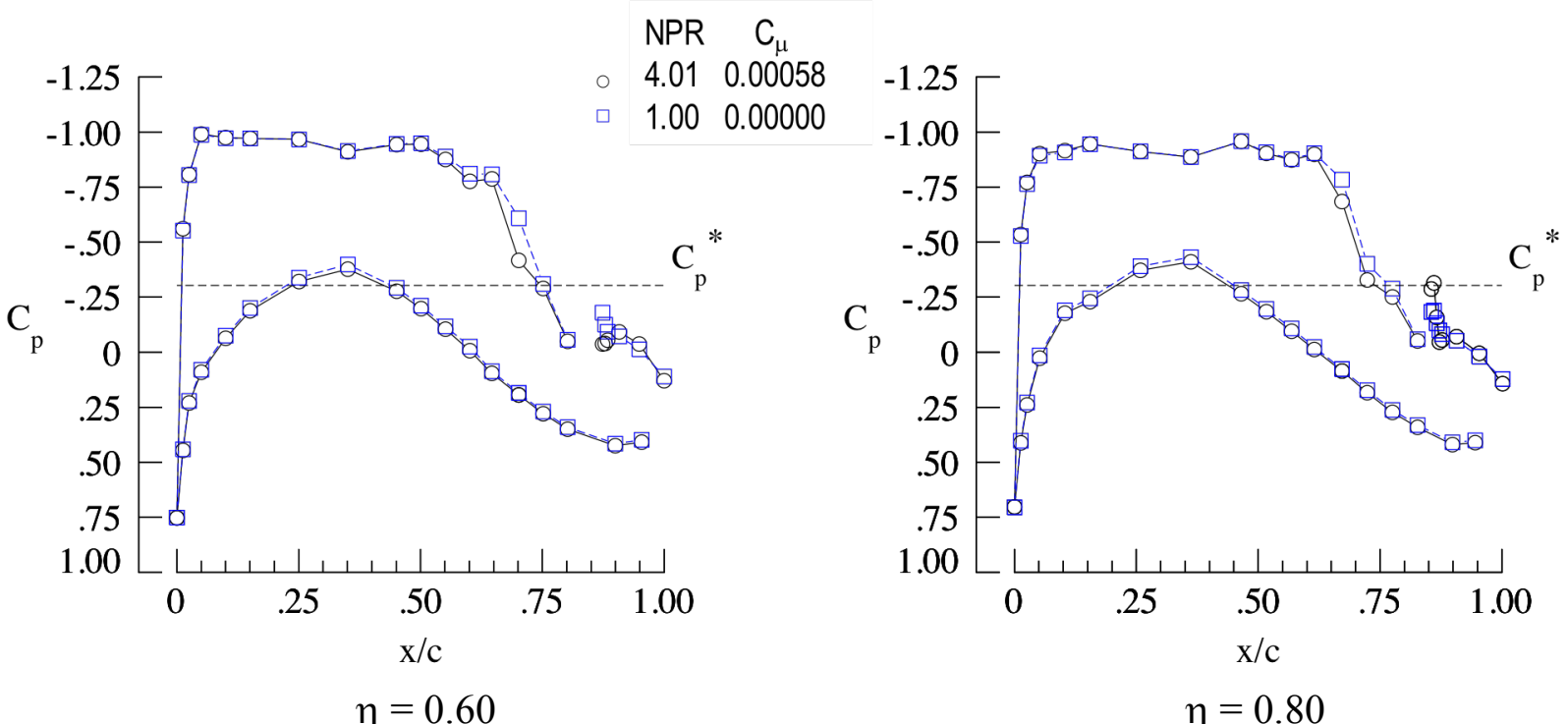

Figure 30. Effect of sweeping jet on wing pressures at design conditions, $0^{\circ}$ flap deflection, AA Actuator, Mach $=0.85, \alpha=3^{0}, \operatorname{Re}_{C}=15 \times 10^{6}$.

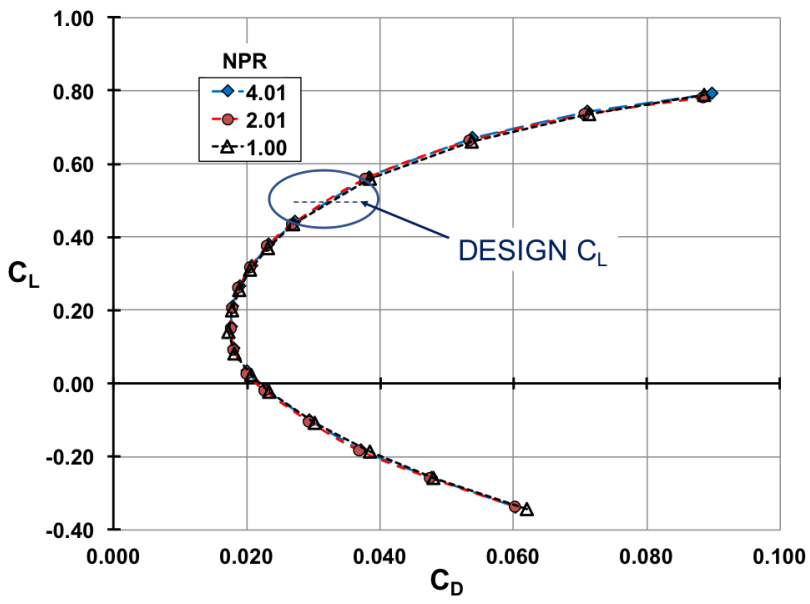

a. Polar

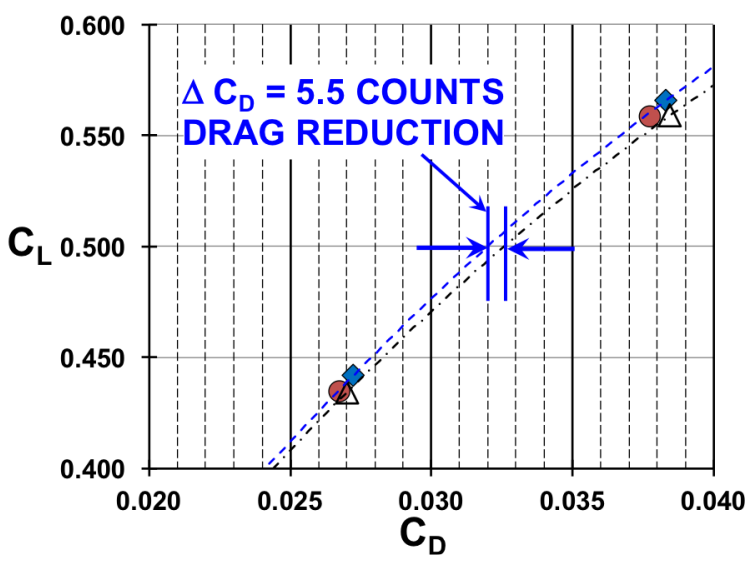

b. Zoomed on Design $C_{L}$

Figure 31. Drag polar using AA actuator, $M a c h=0.85, \operatorname{Re}_{C}=15 \times 10^{6}$.

American Institute of Aeronautics and Astronautics 

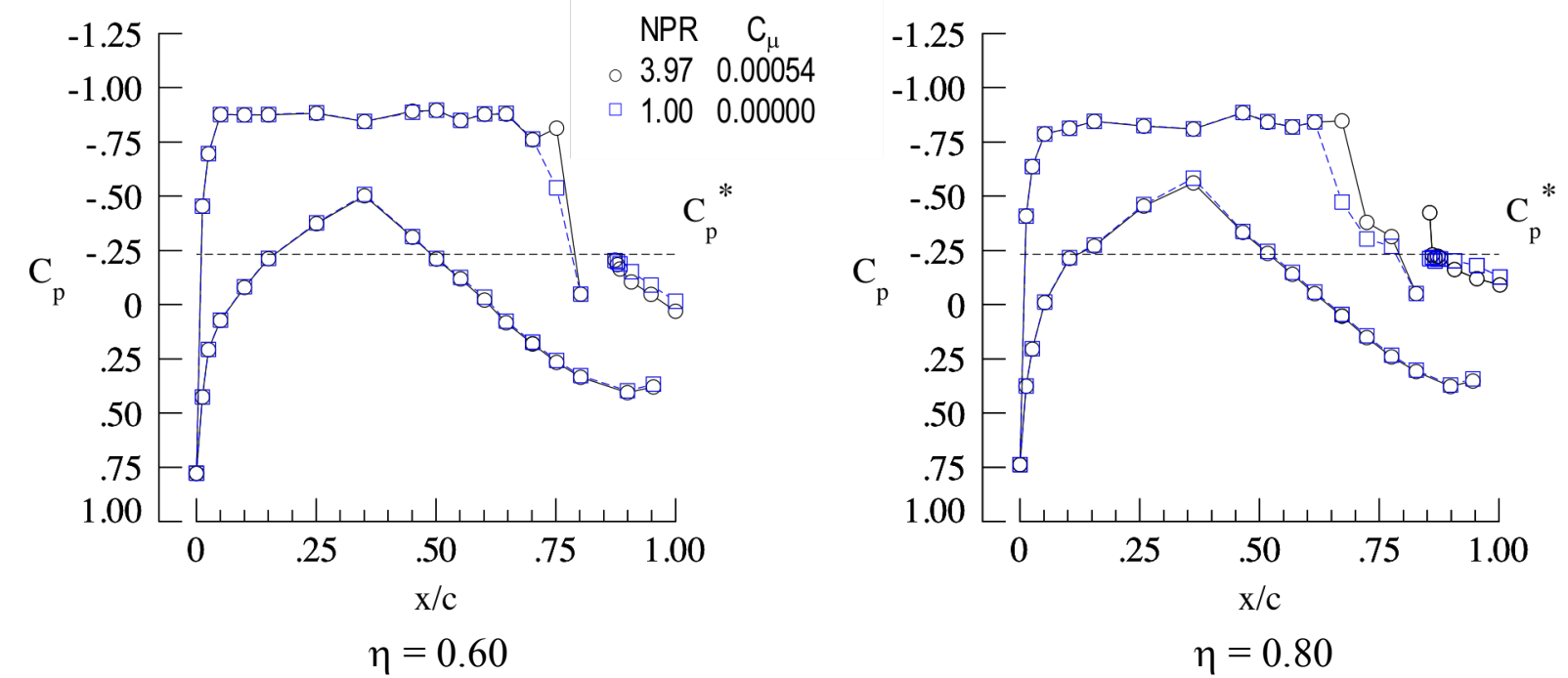

Figure 32. Effect of sweeping jet on wing pressures at off-design conditions, $0^{\circ}$ flap deflection, AA Actuator, $\operatorname{Mach}=0.88, \alpha=3^{0}, \operatorname{Re}_{C}=15 \times 10^{6}$.

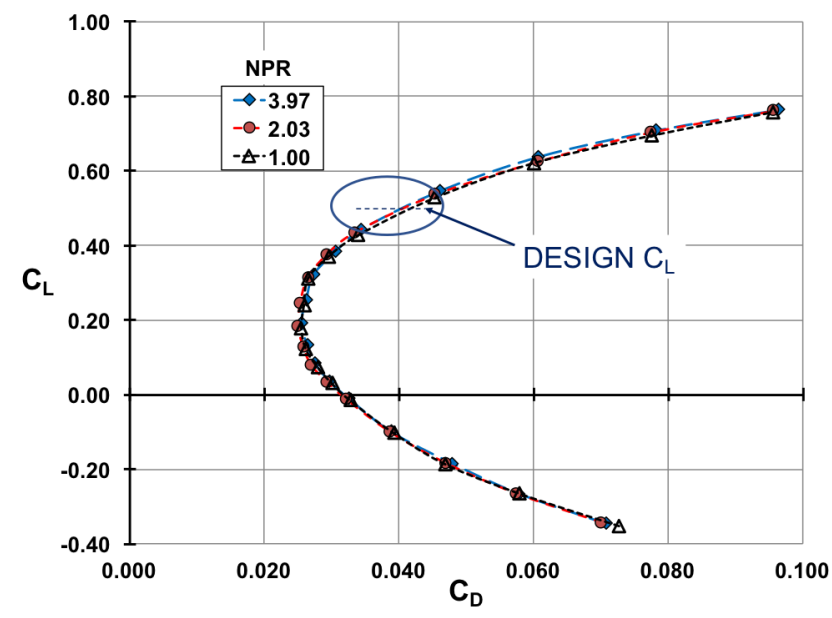

b. Polar

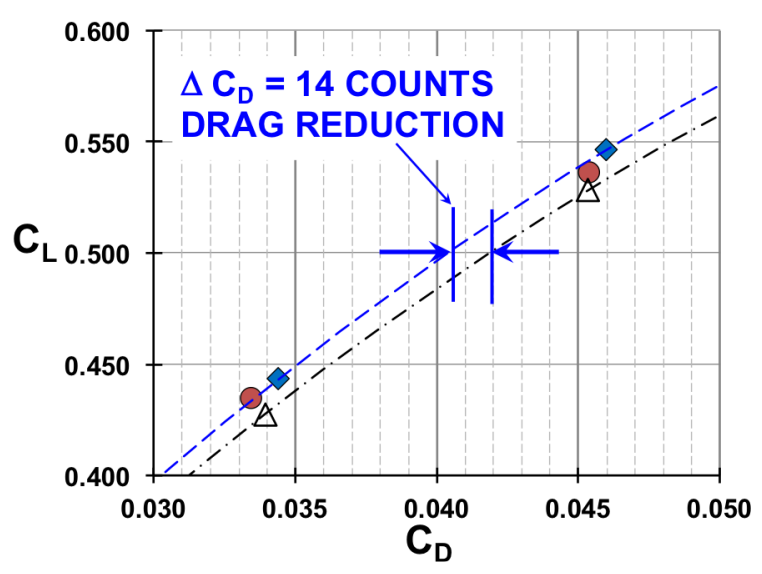

b. Zoomed on Design $C_{L}$

Figure 33. Off-design drag polar using AA actuator, $M a c h=0.88, \operatorname{Re}_{C}=15 \times 10^{6}$. 


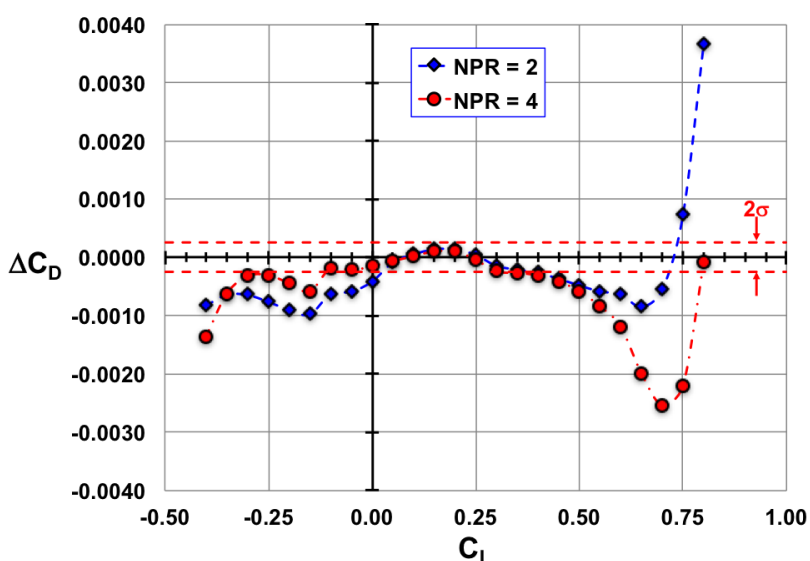

Mach $=0.85$

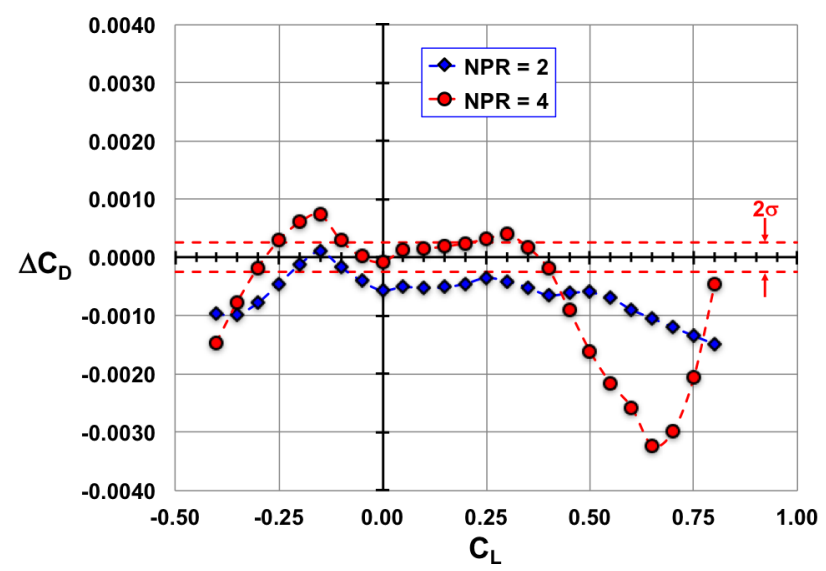

Mach $=0.88$

Figure 34. Angle-of-attack sweep showing drag benefits using AA actuator, $0^{\circ}$ flap deflection, $\operatorname{Re}_{C}=15 \times 10^{6}$.

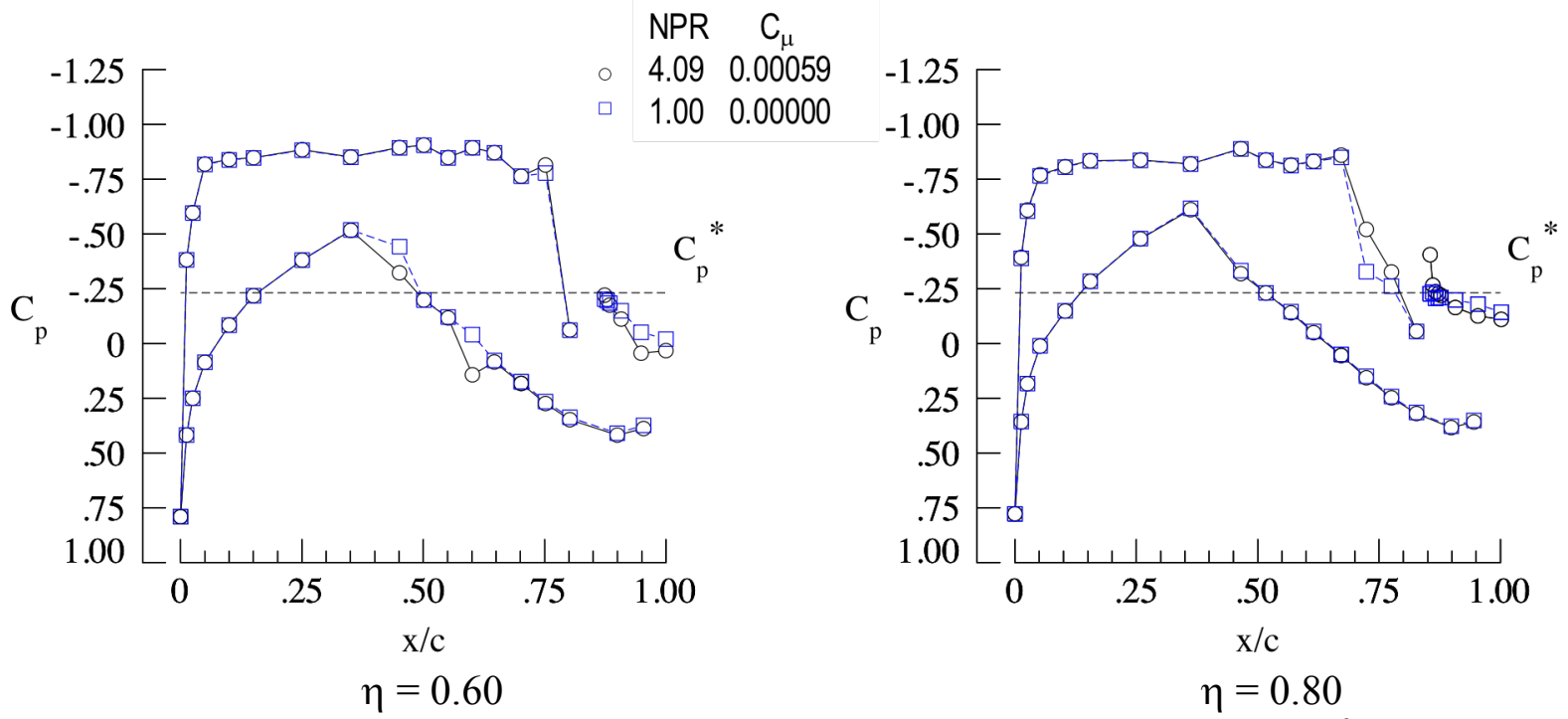

Figure 35. Effect of Actuator AA blowing on wing pressures at off-design conditions, $0^{\circ}$ flap deflection, $\operatorname{Mach}=0.88, \alpha=3^{0}, \operatorname{Re}_{C}=30 \times 10^{6}$.

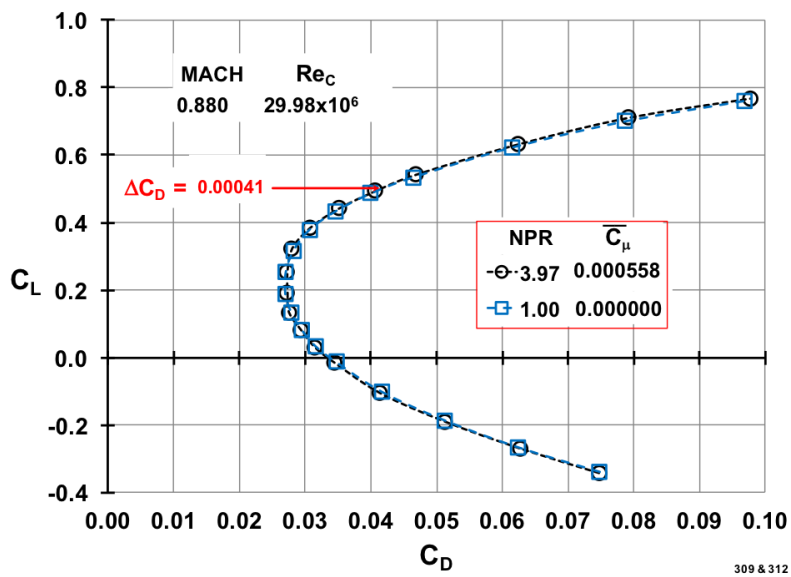

Figure 36. Off-design cruise drag benefit using AA actuator, $M a c h=0.88, \operatorname{Re}_{C}=30 \times 10^{6}$.

American Institute of Aeronautics and Astronautics 


\section{References}

${ }^{1}$ Jones, G.S., Joslin, R.D., "Proceedings of the 2004 NASA/ONR Circulation Control Workshop", NASA/CP-2005213509, June 2005.

2 Jameson, K.K, Marshal, D.D., Golden, R., Paciano, E., Englar, R.J., Gaeta, R.J., Paterson, J. Mason, D., "Part1: The Wind Tunnel Model Design and Fabrication of Cal Poly' AMELIA 10 Foot Span Hybrid Wing-Body Low Noise CESTOL Aircraft,” AIAA Paper 2011-1306, January 2011.

${ }^{3}$ Zeune, C.H., "An Overview of the Air Force's Speed Agile Concept Demonstration Program," AIAA Paper 20131097, January 2013.

${ }^{4}$ Barberie, F.J., Wick, A.T., Hooker, J.R., Zeune, C.H., "Low Speed Powered Lift Testing of a Transonic Cruise Eficient STOL Military Transport,", AIAA Paper 2013-1099, January 2013.

${ }^{5}$ Harrison, N.A., Vassberg, J.C., DeHann, M.A., Gea, L.M., "The Design and Test of a Swept Wing Upper Surface Blowing (USB) Concept," AIAA paper 2013-1102, January 2013.

${ }^{6}$ Jones, G.S., Lin, J.C., Allan, B.G., Milholen, W.E., Rumsey, C.L., Swanson, R.C., "Overview of CFD Validation Experiments for Circulation Control Applications at NASA," IPLC-London June 2008.

${ }^{7}$ Swanson, R.C., Rumsey, C.L., Anders, S.G., "Progress Towards Computational Methods for Circulation Control Airfoils," AIAA Paper 2005-0089, January 2005.

${ }^{8}$ Wick, A.T., Hooker, J.R., Barberie, F.J., Zeune, C.H., "Powered Lift CFD Predictions of a Transonic Cruising STOL Military Transport,", AIAA Paper 2013-1098, January 2013.

9 Jones, G.S., Milholen II, W.E., Fell, J.S., Webb, S.R., Cagle, C.M., "Using Computational Fluid Dynamics and Experiments to Design Sweeping Jets for High Reynolds Number Cruise Configurations", AIAA Paper 2016-3311.

${ }^{10}$ Milholen II, W.E., Jones, G.S., Chan, D.T., Goodliff, S.G., "High-Reynolds Number Circulation Control Testing in the National Transonic Facility (Invited)", AIAA paper 2012-0103, January 2012.

${ }^{11}$ Milholen II, W.E., Jones, G.S., and Cagle, C.M., "NASA High-Reynolds Number Circulation Control Research Overview of CFD and Planned Experiments (Invited)", AIAA Paper 2010-344, January 2010.

${ }^{12}$ Wahls, R.A., “The National Transonic Facility: A Research Retrospective (Invited),” AIAA Paper 2001-16587, January 2001.

${ }^{13}$ Frink, N. T., "Tetrahedral Unstructured Navier-Stokes Method for Turbulent Flows," AIAA Journal, Vol. 36, No. 11, November 1998, pp. 1975-1982.

${ }^{14}$ Campbell, Richard L, "Efficient Viscous Design of Realistic Aircraft Configurations (Invited)", AIAA Paper 982539, June 1998.

${ }^{15}$ Gatlin, G.M, Tomek, W.G., Payne, F.M., and Griffiths, R.C., "Recent Improvements in Semispan Testing at the National Transonic Facility (Invited)", AIAA Paper 2006-508, January 2006.

${ }^{16}$ Woszidlo, R., Nawroth, H., Raghu, S., and Wygnanski, I., "Parametric Study of Sweeping Jet Actuators for Separation Control," AIAA Paper 2010-4247, July 2010.

${ }^{17}$ Pack-Melton, L., “Active Flow Separation Control on a NACA 0015 Wing using Fluidic Actuators,” AIAA Paper 2014-2364, June 2014. 
${ }^{18}$ Koklu, M., "The Effects of Sweeping Jet Actuator Parameters on Flow Separation Control," AIAA Paper 20152485, June 2015.

${ }^{19}$ Pack-Melton, L., Koklu M., Andino, M., C Lin, J.C., and Edelman, L., "Sweeping Jet Optimization Studies,” AIAA Paper 2016- 3170, June 2016.

${ }^{20}$ Jones, G.S., Milholen II, W.E., Goodliff, S.L., "Development of the Dual Aerodynamic Nozzle Model for the NTF Semispan Model Support System,” AIAA Paper 2011- 3170, June 2011.

${ }^{21}$ Mikkelsen, K.L., Olstad, S.J.,"Airflow Calibrations of NASA Langley Research Center Multiple Critical Venturi (MCV) Assemblies," FluiDyne Report 1835, June 1992.

${ }^{22}$ Lynn, K.C., "Development of the NTF-117S Semispan Balance”, AIAA Paper 2010-4542, June 2010.

${ }^{23}$ Lynn, K.C., Rhew, R.D., Acheson, M.J., Jones, G.S., Milholen II, W.E., Goodliff, S.L., "High Reynolds Number Active Blowing Semispan Measurement System Development,” AIAA Paper 2012-3318, June 2012.

${ }^{24}$ Goodliff, S.L., Jones, G.S., Balakrishna, S., Chan, D.T., Milholen, II, W.E., Butler, D., Cagle, C.M., "Force Measurement Improvements to the National Transonic Facility Sidewall Model Support System," AIAA Paper 2016-0648, January 2016.

${ }^{25}$ Chan, D.T., Hooker, J.R., Wick, A.T., Plumley, R.W., Zeune, C.H., Ol, M.V., Demoss, J.A., "Transonic Semispan Aerodynamic Testing of the Hybrid Wing Body with Over Wing Nacelles in the National Transonic Facility," AIAA Paper 2017-0098, January 2017.

${ }^{26}$ Chan, D.T., Milholen II, W.E., Jones, G.S., Goodliff, S.G., "Thrust Removal Methodology for the FAST-MAC Circulation Control Model Tested in the National Transonic Facility," AIAA Paper 2014-2402. 